\title{
Kinetics and Adsorption Studies of Mercury and Lead by Ceria Nanoparticles Entrapped in Tamarind Powder
}

\author{
Rekha Sharma, ${ }^{\dagger}$ Sapna Raghav, ${ }^{\dagger}$ Manjula Nair, ${ }^{\S}$ and Dinesh Kumar*, ${ }^{*}$ (৫) \\ ${ }^{\dagger}$ Department of Chemistry and ${ }^{\ddagger}$ Department of Chemistry, Banasthali Vidyapith, Banasthali, Rajasthan 304022, India \\ ${ }^{\S}$ HBMSU, Academic City, Dubai 71400, UAE \\ "School of Chemical Sciences, Central University of Gujarat, Gandhinagar 382030, India
}

Supporting Information

\begin{abstract}
In this study, novel adsorbent ceria nanoparticles (CeNPs) entrapped in tamarind powder (Tm@ CeNPs) were efficiently utilized for the simultaneous adsorption of aqueous mercury $[\mathrm{Hg}(\mathrm{II})]$ and aqueous lead $[\mathrm{Pb}(\mathrm{II})]$. Surface interactions between the adsorbent and heavy metal ions play an important role in the adsorption process, and the surface morphology can significantly improve the adsorption capacity of the adsorbent. The Langmuir adsorption capacity of $\mathrm{Tm} @ \mathrm{CeNPs}$ for $\mathrm{Hg}$ (II) and $\mathrm{Pb}$ (II) was found to be 200 and $142.85 \mathrm{mg} / \mathrm{g}$, respectively. The surface area of utilized adsorbent was found to be very high,

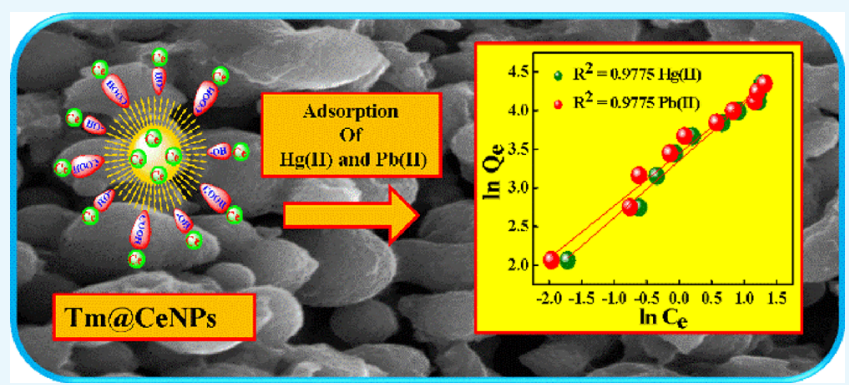
that is, $412 \mathrm{~m}^{2} / \mathrm{g}$. The adsorption kinetics of Tm@CeNPs for both ions follow pseudo-second-order, and the adsorption process is also thermodynamically feasible. Column study favors multilayer adsorption of the heavy metal ion. The spectral analysis of the adsorbent revealed that hydroxyl, carboxylic, and ester groups, as well as CeNPs, are responsible for $\mathrm{Hg}$ (II) and $\mathrm{Pb}$ (II) adsorption. The cost-benefit analysis confirms the economic viability of the synthesized Tm@CeNPs composite for heavy metal removal. The adsorbent is best suited for $\mathrm{Hg}(\mathrm{II})$ adsorption as compared to $\mathrm{Pb}$ (II). This is a novel study on the utilization of tamarind leaf powder with CeNPs for heavy metal ion adsorption and its adsorption mechanism, which has not been reported to date.
\end{abstract}

\section{INTRODUCTION}

With the boom of industries particularly printing, pigment manufacturing, mining, and battery manufacturing industries, the amount of anthropogenic waste emission into the water has been increased too. ${ }^{1}$ Presently, the world is facing a severe problem of heavy metal contamination in water, which affects both plants and animals. ${ }^{2}$ Accumulation of these toxic heavy metal ions (i.e., $\mathrm{Hg}, \mathrm{Pb}, \mathrm{Cd}, \mathrm{Cr}$, and $\mathrm{As}$ ) in the environment leads to critical health problems. Various industries such as lead battery, phosphate fertilizer, electronics, wood, and automobile industries release their effluents which contain $\mathrm{Pb}$ (II) into the water, and in the last few decades, $\mathrm{Pb}$ (II) is regarded as the major source of heavy metal contamination throughout the world. The most toxic heavy metal (i.e., mercury) has the potential to accumulate in the living tissue and to biomagnify in food chains. These heavy metal ions such as mercury $[\mathrm{Hg}(\mathrm{II})]$ and lead $[\mathrm{Pb}(\mathrm{II})]$ can cause various health issues, namely gastrointestinal diseases, liver problems, and nervous system damage. Therefore, the World Health Organization (WHO) has enforced the concentration limit for $\mathrm{Pb}(\mathrm{II})$ and $\mathrm{Hg}(\mathrm{II})$ in drinking water as below 0.01 and 0.001 ppm, respectively. ${ }^{3,4}$ The removal of heavy metal ions has evoked considerable interest for decades. Many conventional methods for the removal of these toxic metals such as chemical precipitation, ${ }^{5}$ electrolysis, ${ }^{6}$ ion exchange, ${ }^{7}$ and adsorption ${ }^{8}$ have been reported. However, these techniques have limitations and are either not effective or economically viable for the heavy metal ion removal at low concentrations. Among them, adsorption and ion exchange is simple and cost-effective as compared to other techniques. 9

The utilization of low-cost adsorbent materials and the effective reduction of heavy metal ion concentration of water are the major advantages of the adsorption technology. It is more advantageous over conventional methods in terms of minimization of biological and/or chemical sludge, high efficiency, low cost, the possibility of metal recovery, and the regeneration of adsorbent. Being cost-effective, the adsorption technology is widely used in heavy metal industries. Many adsorbents have been utilized for heavy metal ion removal from the water, that is, hazelnut shells, ${ }^{11}$ peanut hull, ${ }^{12}$ coconut husk, ${ }^{13}$ modified cellulosic materials, ${ }^{14}$ modified corncobs, ${ }^{15}$ rice hulls, ${ }^{16}$ nanosize metal oxides, ${ }^{17,18}$ activated carbons, ${ }^{19}$ biomaterials, $^{20}$ and polymers, ${ }^{21}$ such as poly(2-aminothiazole $)^{22}$ and poly(1-amino-5-chloroanthraquinone) nanofibrils. $^{23}$ These materials have some drawbacks such as pore size distribution of adsorbent, and they are nonspecific.

Received: August 3, 2018

Accepted: October 18, 2018

Published: November 1, 2018 


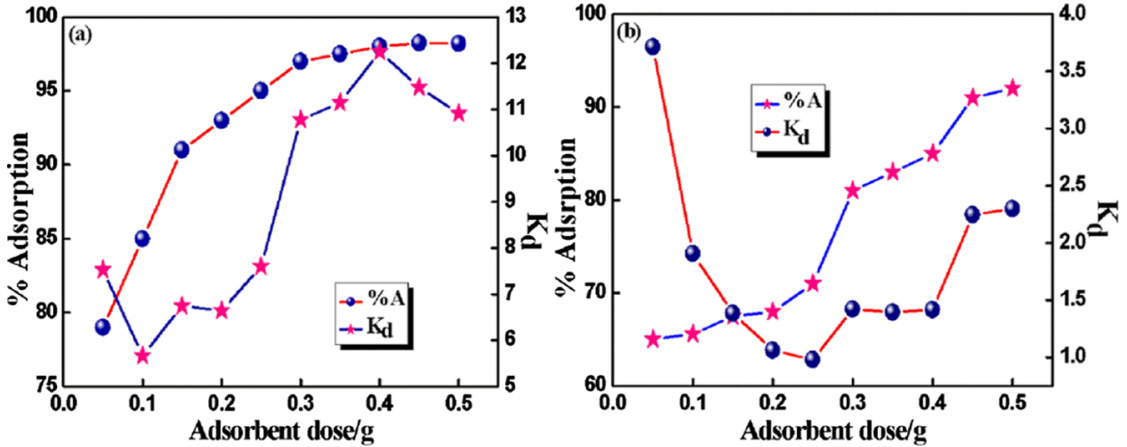

Figure 1. Effect of adsorbent dose for adsorption of (a) $\mathrm{Hg}(\mathrm{II})$ and (b) $\mathrm{Pb}$ (II) on Tm@CeNPs.

Biosorption is a very advantageous technique for heavy metal removal from water because it reduces the biological and/or chemical sludge, does not require nutrients, and has high efficiency in detoxifying effluents. It also offers reversible and fast uptake of the heavy metals with biomass or microorganisms. In the last 2 decades, lots of biological (low-cost) adsorbents have been examined for the removal of toxic metal ions from the aqueous medium. Biosorbents are by-products that are obtained from biomaterial production, and hence they are very cheap also.

The leaves of tamarind can be acquired at a low cost and considered as a waste product. ${ }^{24}$ The leaves possess flavonoids, pectin, water-soluble carbohydrates, tartaric acid, and phenols. These leaves are also used in various food items, that is, soups, stews, salads, and curries in various countries. ${ }^{25}$ Almost all chemical studies on tamarind leaves emphasize on their edibility and the presence of flavonoid compounds. Triterpenoids, lupanone, and lupeol are the other classes of compounds reported from the tamarind leaves, and some essential oils with benzyl benzoate and limonene were also reported as major compounds. ${ }^{26}$ Leaves and fruit of the tamarind tree contain a large amount of natural tartaric acid ranging from 8 to $18 \%$. $^{27-29}$

Literature survey reveals that tamarind is a calcium-rich plant material; $\mathrm{Ca}$ (II) ion has high coordination numbers up to 24 and also has a large size and surface area, which is responsible for the high metal uptake efficiency. Additionally, tamarind leaves have several organic moieties with diverse functional groups which are responsible for the heavy metal uptake such as tartaric acid, flavonoid, triterpenoids, lupanone, lupeol, benzyl benzoate, limonene, diphenyl-ether, ketones, and so forth, and among them, tartaric acid is a major constituent. Therefore, $-\mathrm{COOH}$ group of tartaric acid plays a major role in the adsorption mechanism. Additionally, we have studied the chemical constituents of some other leaves of local plants, that is, Luffa cylindrica, Mentha arvensis, Syzygium cumini, and Azadirachta indica with a comparison to Tamarindus indica leaves (Figure S1 and Table S1). Hereafter, this study confirmed that $T$. indica has a larger number of constituent elements and high abundance of acidic functional groups (Table S1). Therefore, tamarind leaf powder could be successfully utilized as a low-cost alternative biomaterial to prepare tamarind-based adsorbent for the removal of aqueous metal toxicants.

The surface area plays a key role in the efficient adsorption; thus, with this objective, we have synthesized cerium oxide nanoparticles (CeNPs) entrapped in the tamarind leaf powder. To augment the surface area of tamarind powder, CeNPs were entrapped, and this enhances the surface area of tamarind powder from 115 to $412 \mathrm{~m}^{2} / \mathrm{g}$, as we desired.

From the literature review, there is no elucidation of the mechanism for heavy metal adsorption on tamarind-based adsorbents, that is, bark, fruit shell, and so forth, as well as there is no report on tamarind leaves for adsorption of the heavy metal ion. This is the first time exploration of the adsorption mechanism using tamarind-based adsorbent with the incorporation of CeNPs. The beauty of the present adsorbent is its exceptionally high surface area, that is, $412 \mathrm{~m}^{2} /$ $\mathrm{g}$ as well as selectivity toward $\mathrm{Hg}$ (II) and $\mathrm{Pb}(\mathrm{II})$ with good adsorption capacity, that is, 200 and $142.85 \mathrm{mg} / \mathrm{g}$, respectively. The equilibrium adsorption, kinetic, and thermodynamic studies have been carried out for a better consideration of the adsorption process.

The pretreatment of tamarind leaves was carried out at very mild conditions to increase the metal uptake efficiency. We have used fresh tamarind leaves for the synthesis of adsorbent because in fresh tamarind leaves the abundance of functional groups moieties and chemical constituents are more than defoliated leaves.

\section{RESULTS AND DISCUSSION}

2.1. Effect of Adsorbent Dose. In the adsorption process, the adsorbent dose plays an important role because it determines the $\% A$ for a given initial concentration of metal ion $\left(C_{\mathrm{i}}\right)$ solution. The adsorbent dose was varied from 0.1 to $0.5 \mathrm{~g}$ at fixed $\mathrm{Hg}$ (II) and $\mathrm{Pb}$ (II) concentration of $10 \mathrm{ppb}$. Figure 1a,b shows the effect of adsorbent dose on $\% A$ and distribution coefficient $k_{\mathrm{d}}$. The $\% A$ increase with an increase in adsorbent dose up to $0.3 \mathrm{~g}$, after that it reaches an equilibrium. After $0.4 \mathrm{~g}$ adsorbent dose, the increase in $\% A$ was very slow or no increase. The $\% A$ for $\mathrm{Hg}$ (II) and $\mathrm{Pb}$ (II) was found to be 97 and $81 \%$ at $0.3 \mathrm{~g}$ adsorbent dose, on further increase in adsorbent dose, \% A increases from 97 to $98.2 \%$ for $\mathrm{Hg}$ (II) and 81 to $92 \%$ for $\mathrm{Pb}(\mathrm{II})$. From these results, it is confirmed with increase in adsorbent dose, $\% A$ increases up to a certain level; this might be due to a corresponding increase in the binding active sites. However, after a certain level with a further increase in dose, \% $A$ did not increase; this is because the concentration of adsorbing ion may get reduced or may be saturated on the adsorbent sites. Additionally, large amount of adsorbent dose led to greater contact between the adsorbent particles on Tm@CeNPs surface and the adsorbing ions. Hence, the adsorption of $\mathrm{Hg}$ (II) ions on adsorption sites will be high. However, the dose of $0.4 \mathrm{~g}$ of adsorbent showed equilibrium for the adsorption of $\mathrm{Hg}$ (II) because there was no adsorption observed above $0.4 \mathrm{~g}$ of adsorbent dose. Hence, use 

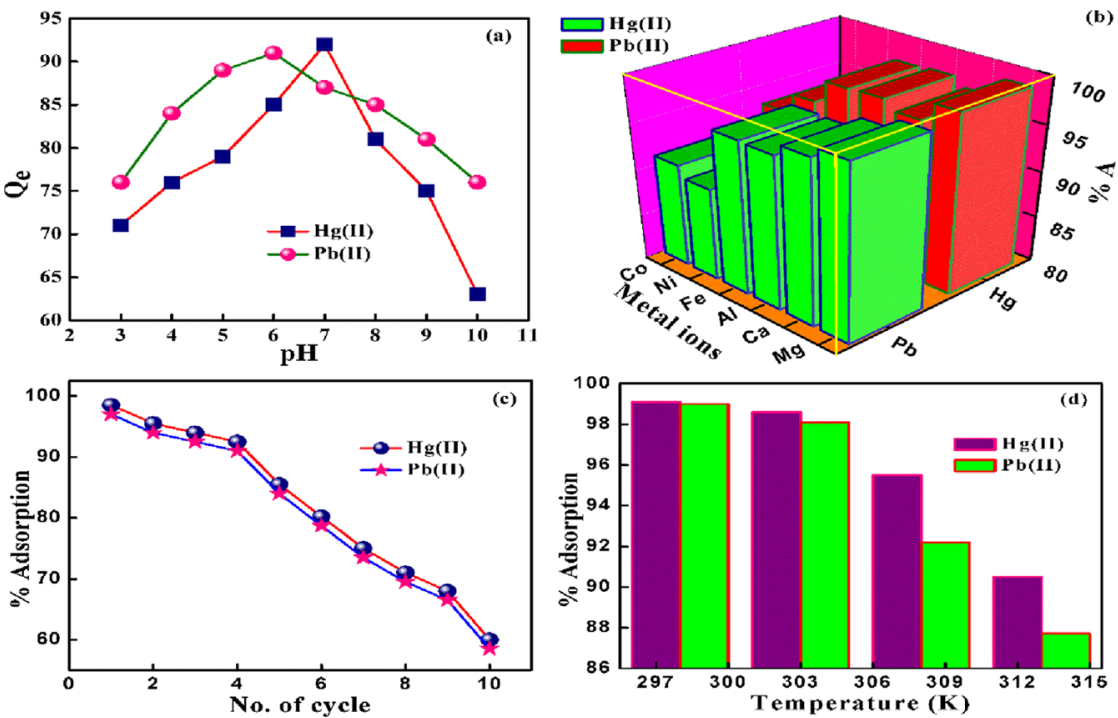

Figure 2. Effect of (a) pH, (b) co-metal ions, (c) regeneration cycle, and (d) temperature on adsorption of $\mathrm{Hg}(\mathrm{II})$ and $\mathrm{Pb}(\mathrm{II})$ on Tm@CeNPs.

of more doses will only lead to wastage of adsorbent. Furthermore, the distribution coefficient curves show the first decrease and then increase in the $k_{\mathrm{d}}$ value which signifies the heterogeneous surface of the adsorbent.

From the overall study of adsorbent dose, the adsorption of $\mathrm{Hg}$ (II) occurred prior to that of $\mathrm{Pb}(\mathrm{II})$.

2.2. Effect of $\mathrm{pH}$. The $\% A$ of both the metal ion increases up to $\mathrm{pH} 6$ for $\mathrm{Pb}$ (II) and $\mathrm{pH} 7$ for $\mathrm{Hg}$ (II), after which the \% $A$ decreases. The charge of the surface of cerium oxide became negative on increasing the $\mathrm{pH}$ because of the increasing deprotonation reaction, which strongly weakened the electrostatic attraction between the metal ion and the negatively charged surface. The surface charge of the adsorbent was positive $\mathrm{pH}<7$ and negative $\mathrm{pH}>7$.

$\mathrm{Pb}$ (II) and $\mathrm{Pb}(\mathrm{OH})^{+}$were found as dominant species of $\mathrm{Pb}$ (II) at $\mathrm{pH}<6.2$ (Figure $2 \mathrm{a}$ ). The CeNPs could react with $\mathrm{Pb}(\mathrm{II})$ and $\mathrm{Pb}(\mathrm{OH})^{+}$to form $\mathrm{CeO}-\mathrm{PbOH}$ and $\mathrm{Ce}_{2} \mathrm{O}_{3}-\mathrm{PbO}$. Consequently, the $\mathrm{Pb}(\mathrm{II})$ adsorption at $\mathrm{pH}<6.2$ occurred because of the outer-sphere surface complexation reaction. The comparative dispersal of $\mathrm{Pb}$ (II) species in solution showed that $\mathrm{Pb}(\mathrm{II})$ mainly existed in the form of $\mathrm{Pb}(\mathrm{OH})^{+}, \mathrm{Pb}_{3}(\mathrm{OH})_{4}{ }^{2+}$, and $\mathrm{Pb}_{4}(\mathrm{OH})_{4}{ }^{4+}$ species at $\mathrm{pH}>6.2 .^{30,31} \mathrm{~Pb}(\mathrm{II})$ is capable to bind cerium oxides and form inner-sphere complexes through the covalent bonds between $\mathrm{Pb}(\mathrm{II})$ and oxygen on Tm@ CeNPs surfaces. Additionally, lead forms precipitate of $\mathrm{Pb}(\mathrm{OH})_{2}$ at high $\mathrm{pH}$ conditions. Therefore, it confirms that the ease of adsorption of aqueous $\mathrm{Pb}$ (II) and $\mathrm{Hg}$ (II) driven by the combined effect of both precipitation and inner-sphere surface complexation.

2.3. Effect of Co-Metal lons and Co-Anions. The interference of co-metal ions during the adsorption was also studied to confirm the selectivity of adsorbent toward $\mathrm{Hg}$ (II) and $\mathrm{Pb}(\mathrm{II})$. For this, an equal concentration of co-metal ions was added into the $\mathrm{Hg}$ (II) and $\mathrm{Pb}$ (II) solution during the adsorption process and analyzed for the residual concentration of different co-metal ions. The result found that the co-metal ions concentration remains the same or decreases negligibly. The order of co-metal ion effect on the adsorption of $\mathrm{Hg}$ (II) and $\mathrm{Pb}$ (II) was found to be $\mathrm{Co}(\mathrm{II})>\mathrm{Ni}$ (II) $>\mathrm{Ca}(\mathrm{II})>\mathrm{Al}$ (III) $>\mathrm{Fe}(\mathrm{III})>\mathrm{Mg}(\mathrm{II})$ and $\mathrm{Ni}(\mathrm{II})>\mathrm{Co}(\mathrm{II})>\mathrm{Al}(\mathrm{III})>\mathrm{Fe}(\mathrm{III})>$ $\mathrm{Ca}(\mathrm{II})>\mathrm{Mg}(\mathrm{II})$ (Figure $2 \mathrm{~b}$ ), respectively.
Additionally, the effect of co-anions was also studied, in which the order of $\% A$ was found to be $\mathrm{PO}_{4}{ }^{3-}>\mathrm{SO}_{4}{ }^{2-}>$ $\mathrm{CO}_{3}{ }^{2-}>\mathrm{NO}_{3}{ }^{-}>\mathrm{Cl}^{-}$for $\mathrm{Hg}(\mathrm{II})$ and $\mathrm{Pb}$ (II) (Figure S2). The ratio of charge to the radius $(z / r)$ of the anions had a close correlation with their affinity to the adsorbents, and the order of $z / r$ is $\mathrm{PO}_{4}{ }^{3-}(3 / 0.238)>\mathrm{SO}_{4}{ }^{2-}(2 / 0.230)>\mathrm{CO}_{3}{ }^{2-}(2 /$ $0.186)>\mathrm{NO}_{3}{ }^{-}(1 / 0.179)>\mathrm{Cl}^{-}(1 / 0.181) . \mathrm{PO}_{4}{ }^{3-}$ and $\mathrm{SO}_{4}{ }^{2-}$ have higher $z / r$ so they have a greater affinity toward adsorbent. $\mathrm{Cl}^{-}$and $\mathrm{NO}_{3}{ }^{-}$showed a lesser effect on adsorption, and this might be due to the low affinity of these ligands.

2.4. Regeneration. For any type of adsorption process, the reuse or regeneration of adsorbent is very essential from the economy point of view. Thus, regeneration of adsorbent has been done up to 10 cycles to inspect the reusability of the adsorbent and metal recovery efficiency. ${ }^{32}$ The desorption of both metals $\mathrm{Hg}$ (II) and $\mathrm{Pb}(\mathrm{II})$ from the Tm@CeNPs surfaces was carried out in $1 \mathrm{~mol} / \mathrm{L} \mathrm{HNO}_{3}$ solution. The adsorption/ desorption results of 10 cycles are given in Figure $2 c$, which shows that the adsorbent perpetuates more than $80 \%$ of its original, at the end of the fourth cycle, and adsorption capacity was slowly reduced after the fifth adsorption/desorption cycle. This may be probably due to the loss of some functional groups of the tamarind because of acid cleavage. The results show that the Tm@CeNPs are frequently reusable and can be utilized extensively in industrial activities.

2.5. Effect of Temperature. Increase or decrease in temperature during the adsorption process alters the adsorption capacity of Tm@CeNPs. The \% A for $\mathrm{Hg}$ (II) and $\mathrm{Pb}$ (II) decreases with increase in temperature from 298 to $313 \mathrm{~K}$ as shown in Figure $2 \mathrm{~d}$, which shows that the \% $A$ decreases by increasing the temperature up to $313 \mathrm{~K}$. This might be due to the increase in mobility of metal ions, with an increase in temperature. This increase in mobility decreases the chelation of metal ion with the adsorbent. Thus, on increasing temperature, the number of metal ions that can be adsorbed on Tm@CeNPs decreases. Additionally, the electrostatic interaction between metal ions and Tm@CeNPs becomes weak at higher temperatures, and the adsorption process is exothermic in nature.

2.6. Effect of Contact Time and Kinetic Studies. Figure $3 a, b$ shows the effect of contact time on the adsorption 

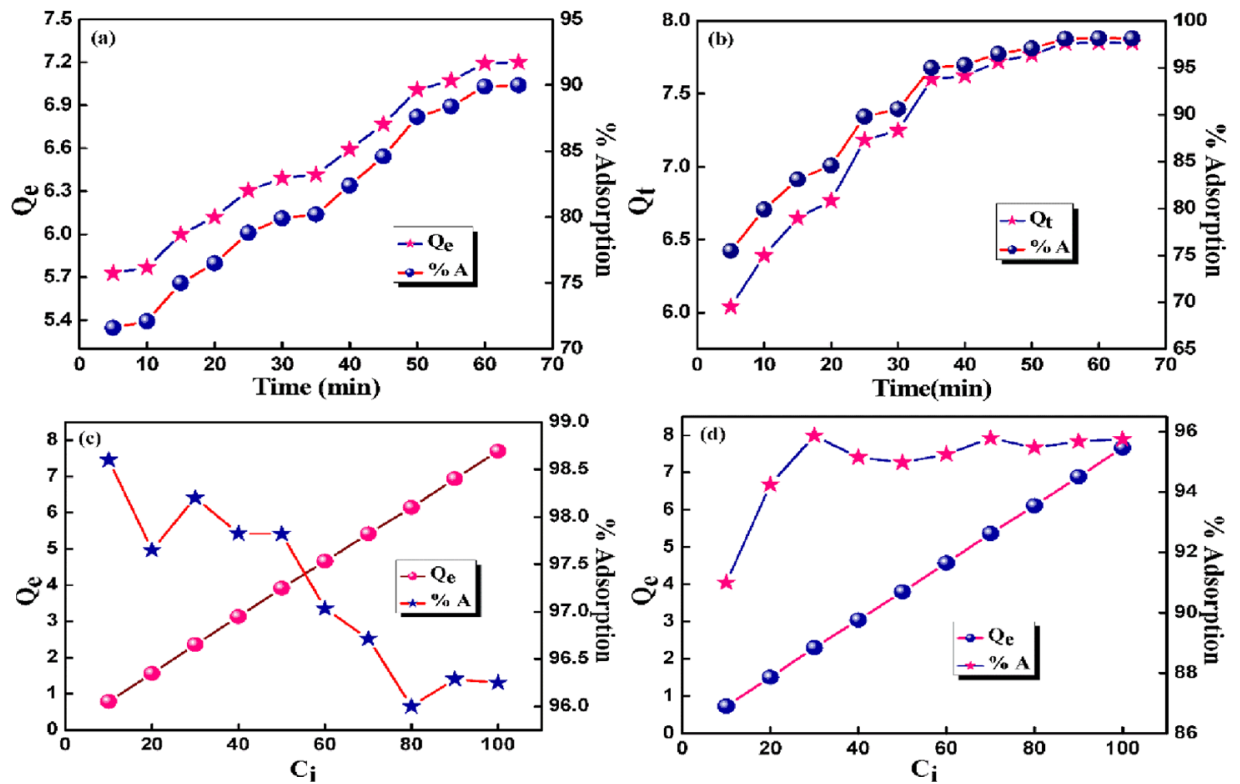

Figure 3. Effect of contact time (a,b) and initial metal ion concentration on adsorption (c,d) of $\mathrm{Hg}(\mathrm{II})$ and $\mathrm{Pb}(\mathrm{II})$ on Tm@CeNPs, respectively.
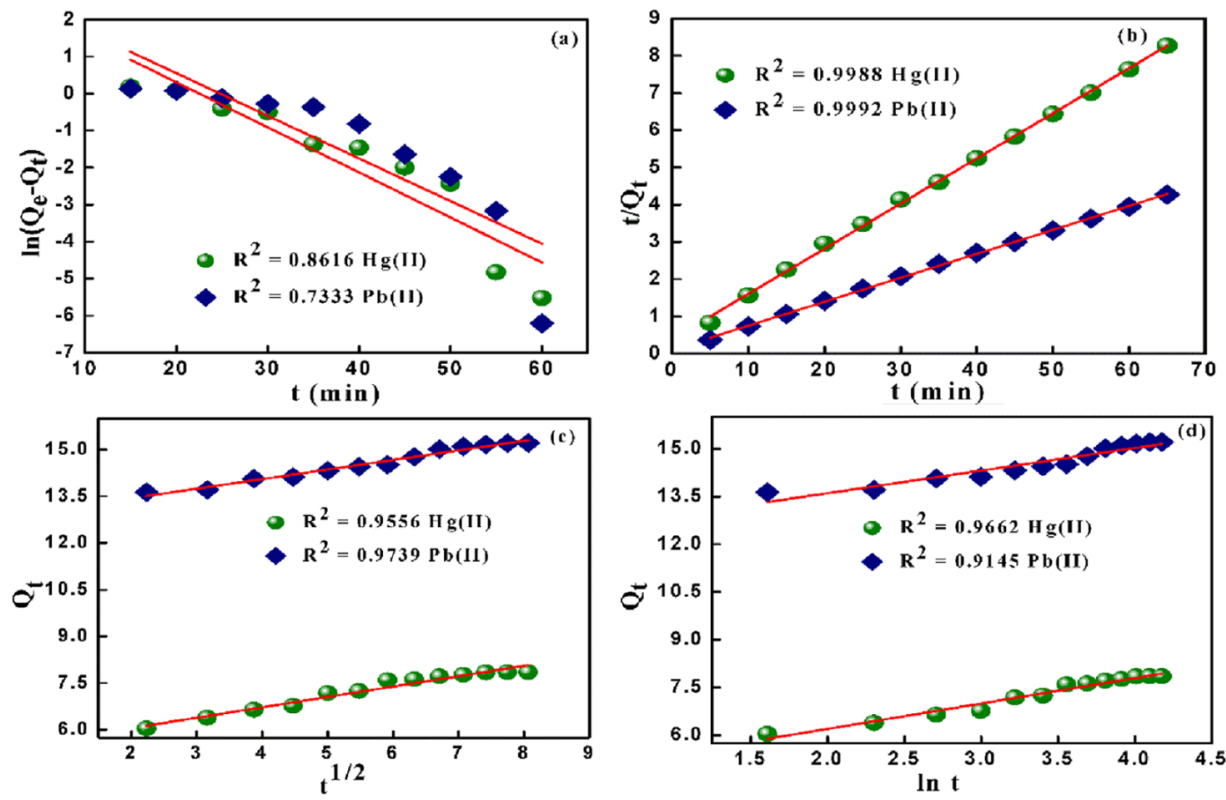

Figure 4. Kinetic model for adsorption of $\mathrm{Hg}(\mathrm{II})$ and $\mathrm{Pb}(\mathrm{II})$ on Tm@CeNPs (a-d) PFO, PSO, IPD, and Elovich, respectively.

efficiency of $\mathrm{Hg}(\mathrm{II})$ and $\mathrm{Pb}(\mathrm{II})$. For fixed mercury and lead ion concentrations, the experiments were carried out in 5-70 $\mathrm{min}$ range of the contact time. Increasing the contact time increased the removal efficiency as there was more time available to interact with adsorption sites on the surfaces of Tm@CeNPs for metal ions. Throughout the first $30 \mathrm{~min}$, the removal efficiency was rapid of $\mathrm{Hg}$ (II) and $\mathrm{Pb}$ (II), then increased slowly, and within $50 \mathrm{~min}$ the adsorption equilibrium was achieved. This may be due to the abundance of vacant surface adsorption sites during the initial stage of adsorption. The remaining vacant surface adsorption sites were quite less in number with further increase in contact time. Furthermore, owing to the repulsive forces functioning between metal ions present in the solution and the already adsorbed metal ions on the solid and those they were not occupied.
In order to complete the understanding of the kinetics of the adsorption process, four different kinetic models were utilized, that is, pseudo-first-order (PFO) (Figure 4a), pseudo-secondorder (PSO) (Figure $4 \mathrm{~b}$ ), intraparticle diffusion (IPD) (Figure $4 \mathrm{c}$ ), and Elovich (Figure $4 \mathrm{~d}$ ). From the $R^{2}$ analysis of kinetic models, the PSO model was best fitted for $\mathrm{Hg}$ (II) and $\mathrm{Pb}(\mathrm{II})$ adsorption on Tm@CeNPs. The order of $R^{2}$ analysis for $\mathrm{Hg}$ (II) and $\mathrm{Pb}(\mathrm{II})$ adsorption was $\mathrm{PSO}>$ Elovich $>\mathrm{IPD}>$ $\mathrm{PFO}$ and $\mathrm{PSO}>\mathrm{IPD}>$ Elovich $>$ PFO, respectively. All three kinetic models well suited the adsorption data of metal ion adsorption except PFO. These models imply that the adsorption mechanism was controlled by particle diffusion and electrostatic interactions. The other kinetic constants of kinetic models are tabulated in Table 1.

2.7. Effect of Initial Metal Concentration $\left(C_{\mathrm{i}}\right)$ and Adsorption Equilibrium Isotherm. The effect of $C_{i}$ on the 
Table 1. Kinetic Constants of $\mathrm{Hg}$ (II) and $\mathrm{Pb}$ (II) Adsorption on Tm@CeNPs

\begin{tabular}{cccccc}
$\mathrm{PFO}$ & $\mathrm{Hg}(\mathrm{II})$ & $\mathrm{Pb}(\mathrm{II})$ & $\mathrm{PSO}$ & $\mathrm{Hg}(\mathrm{II})$ & $\mathrm{Pb}(\mathrm{II})$ \\
$k_{1}$ & 0.12 & 0.11 & $k_{2}$ & 0.038 & 0.03 \\
$q_{\mathrm{e}}$ & 14.87 & 16.4 & $q_{\mathrm{e}}$ & 15.62 & 8.2 \\
$R^{2}$ & 0.86 & 0.83 & $R^{2}$ & 0.99 & 0.99 \\
$\mathrm{IPD}$ & $\mathrm{Hg}(\mathrm{II})$ & $\mathrm{Pb}(\mathrm{II})$ & Elovich & $\mathrm{Hg}(\mathrm{II})$ & $\mathrm{Pb}(\mathrm{II})$ \\
$k_{i}$ & 0.33 & 0.30 & $A$ & 30.07 & 40.06 \\
$X_{i}$ & 5.38 & 12.82 & $B$ & 1.26 & 1.40 \\
$R^{2}$ & 0.95 & 0.97 & $R^{2}$ & 0.96 & 0.91 \\
\hline
\end{tabular}

$\% A$ and $Q_{e}$ of $\mathrm{Tm} @ C e N P s$ for $\mathrm{Hg}$ (II) and $\mathrm{Pb}(\mathrm{II})$ was examined by varying the concentration of metal ions from 10 to $100 \mathrm{ppb}$. Figure $3 \mathrm{c}$,d shows the result of $C_{\mathrm{i}}$ on adsorption of both metal ions by Tm@CeNPs. The \% A for $\mathrm{Hg}$ (II) was subsequently decreased from 98.6 to $96 \%$. For a fixed amount of adsorbent, the decrease in the number of $\mathrm{Hg}$ (II) ions in the solution on increased concentrations is due to several ions competing at the binding sites. The decrease in percent removal is due to the limited total available adsorption sites. While for $\mathrm{Pb}(\mathrm{II}), \% A$ increases slightly from 91 to $95 \%$.

The equilibrium measurement was performed to examine the fundamental adsorption properties regarding adsorption capacity and interaction by using four adsorption models, that is, Freundlich (Figure 5a), Langmuir (Figure 5b), D-R (Figure 5c), and Temkin (Figure 5d). The explanation of these models was tabulated in Table 2 . From the $R^{2}$ analysis of these models, all four models satisfy the adsorption data but the Freundlich model was a best-fitted model for $\mathrm{Hg}$ (II) as well as the $\mathrm{Pb}$ (II) adsorption. The order of $R^{2}$ value for $\mathrm{Hg}(\mathrm{II})$ is Freundlich $\cong$ Temkin $\cong \mathrm{D}-\mathrm{R}>$ Langmuir, and for $\mathrm{Pb}(\mathrm{II})$, the order is Freundlich $\cong$ Temkin $>\mathrm{D}-\mathrm{R}>$ Langmuir. The maximum adsorption capacity calculated from the Langmuir constant was found to be $200 \mathrm{mg} / \mathrm{g}$ for $\mathrm{Hg}$ (II) and $142.85 \mathrm{mg} /$ $\mathrm{g}$ for $\mathrm{Pb}(\mathrm{II})$. The results further indicate that the $\mathrm{Hg}(\mathrm{II})$ adsorption was more prone to adsorbent as compared to the
Table 2. Adsorption Isotherms Constants for $\mathrm{Hg}(\mathrm{II})$ and Pb(II) Adsorption on Tm@CeNPs

\begin{tabular}{cccccc} 
Freundlich & $\mathrm{Hg}(\mathrm{II})$ & $\mathrm{Pb}(\mathrm{II})$ & Langmuir & $\mathrm{Hg}(\mathrm{II})$ & $\mathrm{Pb}(\mathrm{II})$ \\
$n$ & 1.49 & 1.42 & $1 / Q_{\mathrm{m}}$ & 0.005 & 0.007 \\
$1 / n$ & 0.67 & 0.73 & $\mathrm{Q}_{\mathrm{m}}$ & 200 & 142.85 \\
$K_{\mathrm{F}}$ & 31.18 & 28.5 & $K_{\mathrm{L}}$ & 0.17 & 0.30 \\
$R^{2}$ & 0.97 & 0.97 & $R^{2}$ & 0.95 & 0.93 \\
Temkin & $\mathrm{Hg}(\mathrm{II})$ & $\mathrm{Pb}(\mathrm{II})$ & $\mathrm{D}-\mathrm{R}$ & $\mathrm{Hg}(\mathrm{II})$ & $\mathrm{Pb}(\mathrm{II})$ \\
$A_{\mathrm{T}}$ & 3.43 & 4.36 & $q_{\mathrm{m}}$ & 64.71 & 63.43 \\
$B_{\mathrm{T}}$ & 25.97 & 24.12 & $K_{\mathrm{D}-\mathrm{R}}$ & 0.217 & 0.148 \\
$B$ & 95.40 & 102.71 & $E_{\mathrm{m}}$ & 1.51 & 1.83 \\
$R^{2}$ & 0.977 & 0.975 & $R^{2}$ & 0.97 & 0.95 \\
\hline
\end{tabular}

$\mathrm{Pb}$ (II). The $1 / n$ and $K_{\mathrm{L}}$ value signifies the favorable adsorption between the metal ions and the adsorbent.

The $q_{\mathrm{m}}$ value obtained from the $\mathrm{D}-\mathrm{R}$ model also agrees with Langmuir. The mean free energy calculated by $\mathrm{D}-\mathrm{R}$ signifies that the physisorption process occurs during adsorption. The Temkin constants signify favorable binding between metal ions and adsorbents. The values for another constant of the adsorption models are tabulated in Table 2.

2.8. Studies for Selectivity. The synthesized Tm@CeNPs selectively adsorb $\mathrm{Hg}$ (II) and $\mathrm{Pb}$ (II) metal ions because these both ions have the more capability to form a covalent bond with the surface oxygen of Tm@CeNPs, and these two ions also get precipitated at high $\mathrm{pH}$ conditions. The study of the effect of interfering ions on adsorption also confirms the selectivity of adsorbent toward $\mathrm{Hg}$ (II) and $\mathrm{Pb}$ (II). The order of co-metal ion effect on the adsorption of $\mathrm{Hg}$ (II) and $\mathrm{Pb}$ (II) metal ions was $\mathrm{Co}$ (II) $>\mathrm{Ni}$ (II) $>\mathrm{Ca}$ (II) $>\mathrm{Al}$ (III) $>\mathrm{Fe}($ III) $>$ $\mathrm{Mg}$ (II) and $\mathrm{Ni}(\mathrm{II})>\mathrm{Co}(\mathrm{II})>\mathrm{Al}(\mathrm{III})>\mathrm{Fe}(\mathrm{III})>\mathrm{Ca}(\mathrm{II})>$ $\mathrm{Mg}$ (II) (Figure 2b), respectively.

The reason behind the selective adsorption of lead and mercury is its high effective nuclear charge in comparison to above all co-metal ions because the effective nuclear charge increases ongoing downward in periodic table due to the
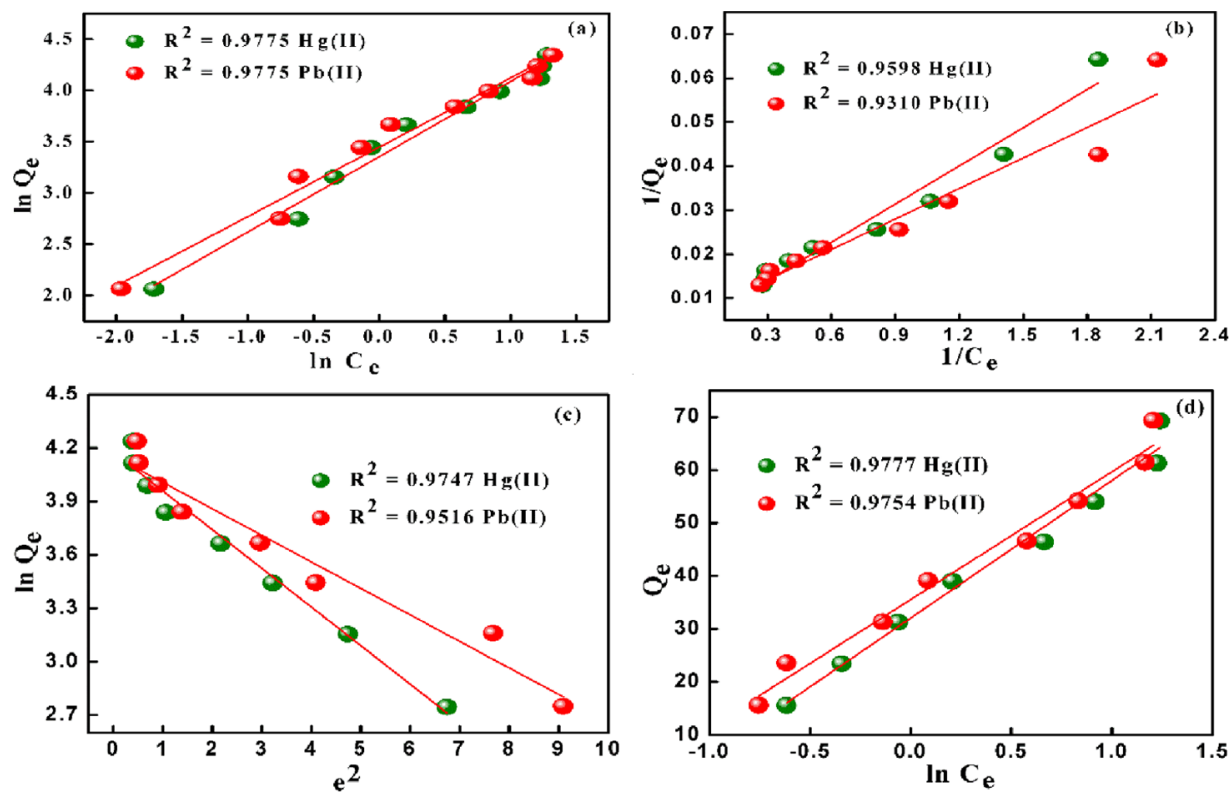

Figure 5. Adsorption isotherm model for adsorption of $\mathrm{Hg}(\mathrm{II})$ and $\mathrm{Pb}(\mathrm{II})$ on Tm@CeNPs (a-d) Freundlich, Langmuir, D-R, and Temkin, respectively. 
involvement of a greater number of d-orbitals. Hence, lead and mercury show stronger attraction than other co-metal ions.

\section{THERMODYNAMIC PARAMETERS}

The thermodynamic parameters, such as Gibbs free energy, enthalpy, and entropy, reveals the information about the adsorption process. These thermodynamic parameters have been calculated using the van't Hoff plot (Figure 6). In this

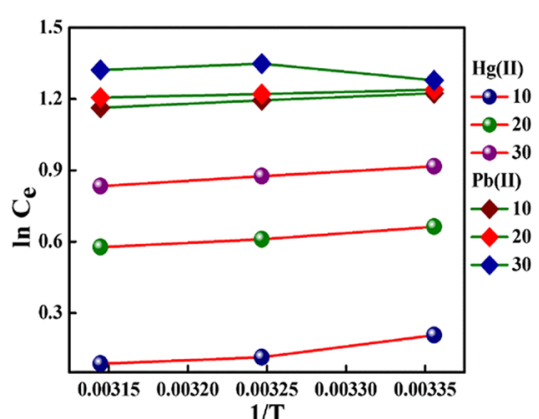

Figure 6. Linear dependence of $\ln C_{\mathrm{e}}$ on $1 / T$ based on the adsorption thermodynamic.

study, the value of $\Delta G$ found negative for both metal ion adsorption processes, which means that the adsorption of $\mathrm{Hg}(\mathrm{II})$ and $\mathrm{Pb}(\mathrm{II})$ was a feasible process. The negative value of $\Delta H$ for both the metal ion adsorption reveals that the adsorption process was exothermic and the positive value of $\Delta S$ reveals spontaneity of the process (Table 3 ).

\section{COLUMN STUDIES}

To study the adsorption of $\mathrm{Hg}$ (II) and $\mathrm{Pb}(\mathrm{II})$ onto $\mathrm{Tm} @$ CeNPs, different linear and nonlinear column models were utilized which are Thomas (Figure 7a), Yoon-Nelson (Figure $7 \mathrm{~b}$ ), Yan (Figure 7c), and Clark (Figure $7 \mathrm{~d}$ ) models. $K_{\mathrm{Th}}(\mathrm{mL} /$ $\mathrm{min} / \mathrm{mg}), K_{\mathrm{YN}}(\mathrm{mL} / \mathrm{min} / \mathrm{mg})$, and $K_{\mathrm{y}}$ are rate constants of Thomas, Yoon-Nelson, and Yan models, respectively. $q_{\mathrm{y}}$ and $q_{\mathrm{T}}$ are the maximum adsorption capacity $(\mathrm{mg} / \mathrm{g})$ and the maximum solid-phase concentration of the solute $(\mathrm{mg} / \mathrm{g})$ of adsorbent calculated by Yan and Thomas models, respectively. The breakthrough (sampling) time is represented as $t$ ( $\mathrm{min}$ ), and the time required for $50 \%$ adsorbate breakthrough ( $\mathrm{min}$ ) is $T$. The exponent of the Freundlich isotherm is denoted as $n$, and $A$ and $r$ are the parameters of the kinetic equation. From the $R^{2}$ analysis of column models, the Yoon-Nelson model was best fitted for both the metal ions. The order for $\mathrm{Hg}$ (II) is Yoon-Nelson > Clark > Thomas $\cong$ Yan and for $\mathrm{Pb}(\mathrm{II})$ is Yoon-Nelson $>$ Clark $>$ Thomas $>$ Yan. Clark models further prove the multilayer type of adsorption. The column data match with the adsorption data, both follow the Freundlich model. The adsorption capacity obtained from the Thomas model was 6450 and $5540 \mathrm{mg} / \mathrm{g}$ for $\mathrm{Hg}$ (II) and $\mathrm{Pb}(\mathrm{II})$, respectively. The other required constants of column models are recorded in Table 4.

\section{COST ANALYSIS}

Cost is a key factor in the choice of adsorbent used in the industry. The Tm@CeNPs were synthesized by utilizing the analytical reagent grade chemicals. Presently, the cost of Tm@ CeNPs adsorbent is around US\$ 30.79 per $\mathrm{kg}$ in the lab. Additionally, in the future, industrial-grade raw materials will replace the analytical-grade chemicals for the large-scale synthesis of adsorbent, which will decrease the cost of adsorbent and increase their application substantially.

\section{FIELD STUDY}

The samples of industrial wastewater for the field study experiments were collected from an industrial area nearby Banasthali Vidyapith to check the suitability of Tm@CeNPs as the adsorbent (Table S2). The batch study was conducted for the adsorption of these toxic metals using different doses of Tm@CeNPs (Figure S3). For this study, 3 g of adsorbent was taken for $1000 \mathrm{~mL}$ of industrial wastewater into a beaker. Now, this solution was shaken at room temperature for $40 \mathrm{~min}$, and then the concentration of both metal ions and the water quality parameters were measured, and data are recoded in Table S2. Results demonstrate that all the water quality parameters and the concentration of $\mathrm{Hg}(\mathrm{II})$ and $\mathrm{Pb}(\mathrm{II})$ from the treated water are below than the permissible limit, which is in good agreement with the adsorption data of batch experiment. Hence, the present study reveals that the removal of $\mathrm{Hg}$ (II) and $\mathrm{Pb}(\mathrm{II})$ ions from wastewater using Tm@CeNPs is also good for the field level.

\section{ADSORPTION MECHANISM}

The adsorption performance of the Tm@CeNPs may coordinate with $\mathrm{Pb}(\mathrm{II})$ or $\mathrm{Hg}(\mathrm{II})$ through carboxyl $(-\mathrm{COOH}$ or $-\mathrm{COOR})$, hydroxyl $(-\mathrm{OH})$, and/or $\mathrm{M}-\pi$ interaction. The adsorption of heavy metal ion may be due to the electrostatic interaction between positively charged metal ion and the carboxyl and hydroxyl groups of tamarind. Additionally, CeNPs also facilitate heavy metal adsorption by electrostatic interactions and complexation. Figure 8 shows the adsorption mechanism of metal ions. The comparison of adsorption capacity of Tm@CeNPs with previously synthesized adsorbents is given in Table 5 .

\section{CHARACTERIZATION}

Figure 9 shows the Brunauer-Emmett-Teller (BET) $\mathrm{N}_{2}$ adsorption-desorption isotherms of type IV, and the

Table 3. Thermodynamic Parameters for $\mathrm{Hg}(\mathrm{II})$ and $\mathrm{Pb}(\mathrm{II})$ Adsorption on Tm@CeNPs

\begin{tabular}{|c|c|c|c|c|c|c|c|c|c|}
\hline \multirow[b]{2}{*}{ metal ions } & \multicolumn{2}{|c|}{$\Delta H(\mathrm{~kJ} / \mathrm{mol})$} & \multicolumn{2}{|c|}{$\Delta G(\mathrm{~kJ} / \mathrm{mol})$} & \multicolumn{5}{|c|}{$\Delta S(\mathrm{~J} / \mathrm{mol})$} \\
\hline & $C_{\mathrm{o}}$ & & $298 \mathrm{~K}$ & $303 \mathrm{~K}$ & $308 \mathrm{~K}$ & $298 \mathrm{~K}$ & $303 \mathrm{~K}$ & $308 \mathrm{~K}$ & $R^{2}$ \\
\hline \multirow[t]{3}{*}{$\mathrm{Hg}(\mathrm{II})$} & 10 & -4.7 & -4.2 & -4.3 & -4.4 & 1.67 & 1.40 & 1.15 & 0.83 \\
\hline & 20 & -3.3 & -1.7 & -1.7 & -1.8 & 5.49 & 5.31 & 5.12 & 0.97 \\
\hline & 30 & -3.2 & -0.9 & -1.0 & -1.02 & 7.69 & 7.50 & 7.50 & 0.99 \\
\hline \multirow[t]{3}{*}{$\mathrm{Pb}(\mathrm{II})$} & 10 & -2.3 & -0.6 & -0.6 & -0.6 & 10.17 & 10.03 & 9.91 & 0.99 \\
\hline & 20 & -1.2 & -1.7 & -1.8 & -1.8 & 10.27 & 10.20 & 10.13 & 0.99 \\
\hline & 30 & -1.75 & 4.3 & -4.4 & -4.4 & 20.44 & 20.3 & 20.25 & 0.84 \\
\hline
\end{tabular}



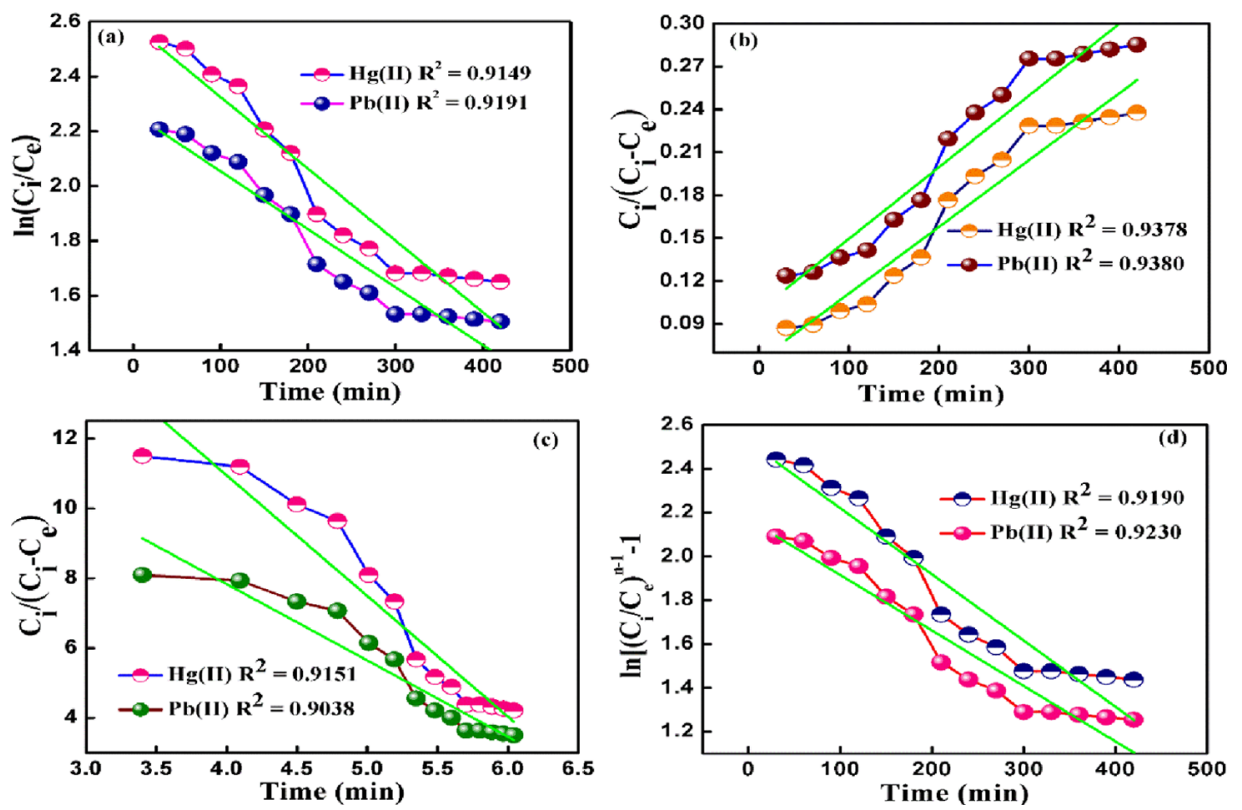

Figure 7. Column models for adsorption of $\mathrm{Hg}(\mathrm{II})$ and $\mathrm{Pb}(\mathrm{II})$ on Tm@CeNPs (a-d) Thomas, Yoon-Nelson, Yan, and Clark models.

Table 4. Column Parameters for $\mathrm{Hg}$ (II) and $\mathrm{Pb}(\mathrm{II})$ Adsorption

\begin{tabular}{|c|c|c|c|c|c|}
\hline Thomas & $\mathrm{Hg}(\mathrm{II})$ & $\mathrm{Pb}(\mathrm{II})$ & Yan & $\mathrm{Hg}(\mathrm{II})$ & $\mathrm{Pb}(\mathrm{II})$ \\
\hline$K_{\mathrm{Th}}$ & $4 \times 10^{-5}$ & $4 \times 10^{-5}$ & $K_{\mathrm{y}}$ & 0.0034 & 0.0021 \\
\hline$q_{\mathrm{Th}}(\mathrm{mg} / \mathrm{g})$ & 6450 & 5540 & $q_{\mathrm{y}}(\mathrm{mg} / \mathrm{g})$ & 427.20 & 375.12 \\
\hline$R^{2}$ & 0.91 & 0.91 & $R^{2}$ & 0.091 & 0.90 \\
\hline Yoon-Nelson & $\mathrm{Hg}$ (II) & $\mathrm{Pb}(\mathrm{II})$ & Clark & $\mathrm{Hg}(\mathrm{II})$ & $\mathrm{Pb}(\mathrm{II})$ \\
\hline$K_{\mathrm{YN}}$ & 4.66 & 5.01 & $R$ & 0.003 & 0.0025 \\
\hline$\tau$ & 0.012 & 0.017 & $A$ & 12.4 & 8.67 \\
\hline$R^{2}$ & 0.93 & 0.93 & $R^{2}$ & 0.91 & 0.92 \\
\hline
\end{tabular}

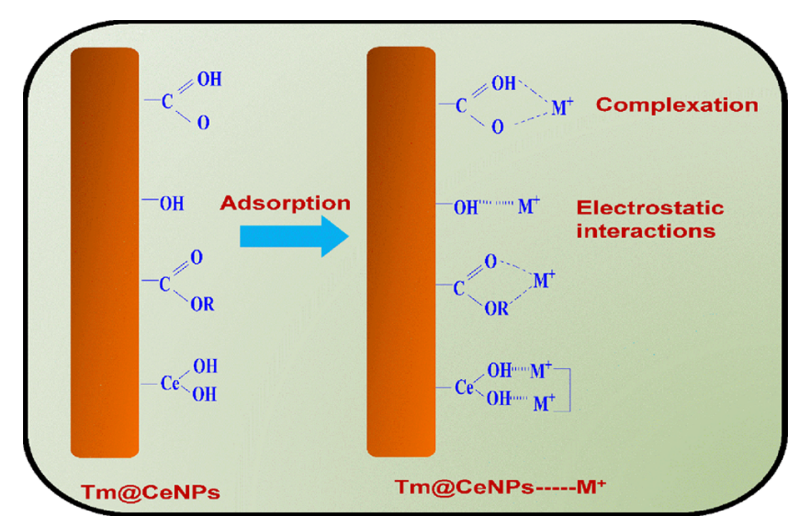

Figure 8. Adsorption mechanism of metal ion adsorption on Tm@ CeNPs.

corresponding pore size distributions are shown in Figure 9a of Tm@CeNPs. The hysteresis loop (type IV) indicates the presence of both micropores and mesopores in the composite. The distributions of the pore size, surface area, and the pore volume for CeNPs, activated tamarind fresh leaves (ATFL), and Tm@CeNPs are tabulated in Table 6. The BET surface area, pore size, and the pore volume of the Tm@CeNPs were found to be much higher as compared to the pure CeNPs and ATFL, which was $412 \mathrm{~m}^{2} / \mathrm{g}, 1.5 \mathrm{~nm}$ and $0.523 \mathrm{~cm}^{3} / \mathrm{g}$, respectively, while the surface area of CeNPs and ATFL was 203 and $115 \mathrm{~m}^{2} / \mathrm{g}$, respectively.
Table 5. Comparison of Adsorption Capacity of Tm@ CeNPs with Other Adsorbents

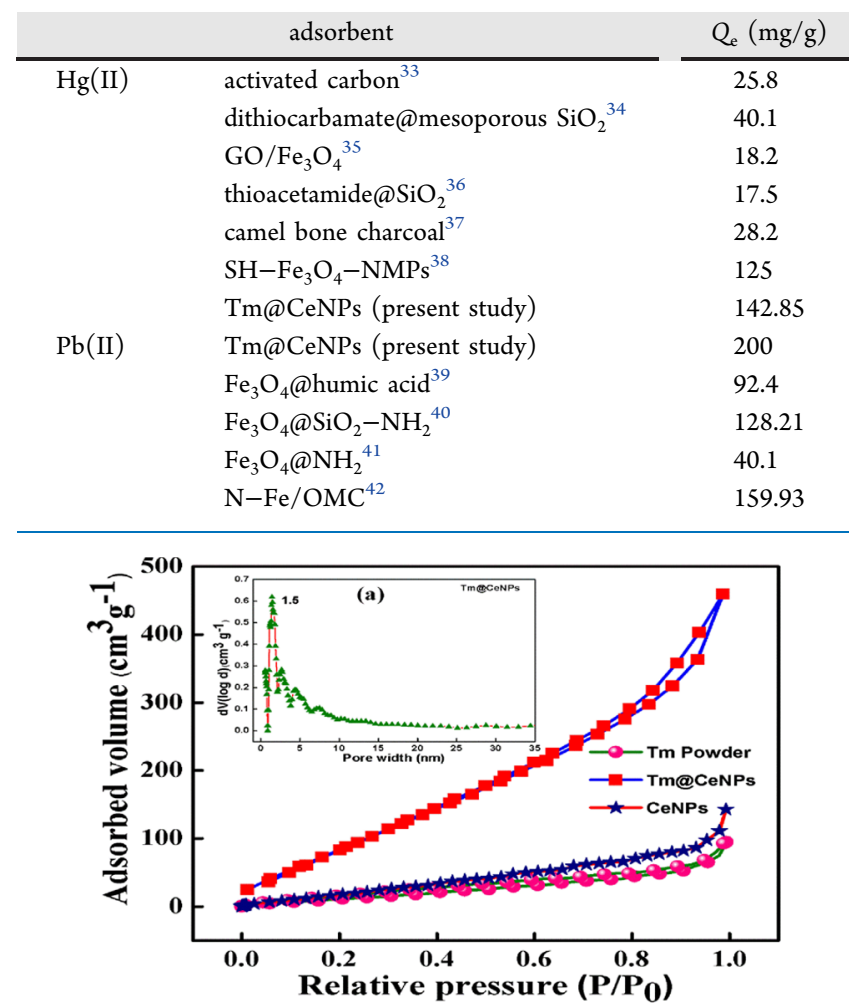

Figure 9. Hysteresis curve of type IV for ATFL powder, CeNPs, and Tm@CeNPs.

8.1. Field Emission Scanning Electron MicroscopyEnergy Dispersive X-ray Spectroscopy. The surface morphology and elemental composition of Tm@CeNPs, Tm@CeNPs-Hg(II), and Tm@CeNPs-Pb(II) were analyzed by field emission scanning electron microscopy (FESEM)-energy dispersive X-ray (EDX) analysis. Figure $10 \mathrm{a}-\mathrm{c}$ shows the EDX spectra of adsorbent before and after 
Table 6. BET Surface Area, Pore Volume, and Pore Size of Adsorbents

\begin{tabular}{lccc}
\multicolumn{1}{c}{ sample } & $\begin{array}{c}\text { BET surface area } \\
\left(\mathrm{m}^{2} / \mathrm{g}\right)\end{array}$ & $\begin{array}{c}\text { total pore volume } \\
\left(\mathrm{cm}^{3} / \mathrm{g}\right)\end{array}$ & $\begin{array}{c}\text { pore size } \\
(\mathrm{nm})\end{array}$ \\
ATFL powder & 115 & 0.423 & 2.8 \\
CeNPs & 203 & 0.503 & 2.4 \\
Tm@CeNPs & 412 & 0.523 & 1.5 \\
\hline
\end{tabular}

$\mathrm{Hg}(\mathrm{II})$ and $\mathrm{Pb}(\mathrm{II})$ adsorption. The main elements shown in the EDX spectra of Tm@CeNPs are C, O, and Ce, while after adsorption of $\mathrm{Hg}(\mathrm{II})$ and $\mathrm{Pb}(\mathrm{II})$, these two element's peak is also added in the spectra of Tm@CeNPs. The surface morphology of the tamarind dried leaves, CeNPs, Tm@ CeNPs, Tm@CeNPs-Hg(II), and Tm@CeNPs-Pb(II) is shown in Figure 10d-h, respectively. The CeNPs show in Figure 10e are spherical, after the coating of tamarind powder the size of spherical-shaped CeNPs becomes broader as shown in Figure 10f. After $\mathrm{Hg}(\mathrm{II})$ and $\mathrm{Pb}$ (II) adsorption, the surface morphology of Tm@CeNPs changes, which signifies the adsorption of these heavy metal ions on the adsorbent. The elemental composition of these three adsorbents is also confirmed by mapping images, that is, Figure 10i-k for Tm@CeNPs, Tm@CeNPs-Hg(II), and Tm@CeNPs-Pb(II), respectively.

8.2. X-ray Photoelectron Spectroscopy. The surface composition, elemental oxidation states, and binding energy of each element involved in the adsorbent before and after adsorption were analyzed by X-ray photoelectron spectroscopy (XPS) analysis. The main elements of Tm@CeNPs are C, O, and $\mathrm{Ce}$ and after adsorption, $\mathrm{Hg}$ (II) and $\mathrm{Pb}(\mathrm{II})$ are also found.

Oxygen deconvolution spectra O 1s for Tm@CeNPs show three important signals at 533.01, 531.22, and $529.54 \mathrm{eV}$ (Figure 11a), which show the interaction of oxygen of chemisorbed water, hydroxyl group, and oxide ion. There is a change in the binding energy of these three signals after the surface modification by heavy metal ion interaction of Tm@ CeNPs. A decrease in the signals by $\sim 0.28,0.09$, and $0.14 \mathrm{eV}$ was observed, respectively (Figure $11 \mathrm{~b}$ ), which might be due to the new interaction between the adsorbent and metal ion.

Deconvolution spectra of C 1s for Tm@CeNPs show three peaks at 285.26, 287.38, and $288.44 \mathrm{eV}$ (Figure 11c) corresponding to $\mathrm{C}-\mathrm{C} / \mathrm{C}=\mathrm{C}, \mathrm{C}-\mathrm{O}-\mathrm{C} / \mathrm{C}-\mathrm{OH}$, and $\mathrm{C}=$ $\mathrm{O}^{28}$ After loading metal ions (Figure $11 \mathrm{~d}$ ), $\mathrm{C}-\mathrm{C} / \mathrm{C}=\mathrm{C}$ functional groups content decreased from 83.01 to $48.73 \%$, while $\mathrm{C}-\mathrm{O}-\mathrm{C} / \mathrm{C}-\mathrm{OH}$ and $\mathrm{C}=\mathrm{O}$ functional groups content significantly increased from 8.73 to $41.48 \%$ and 8.27 to $9.79 \%$ (Table 7), respectively. The \% composition of functional groups was calculated using casa XPS software. Hence, the increased percentage of oxygen-containing functional groups indicates the importance and their active role in the interaction with $\mathrm{Hg}(\mathrm{II})$ and $\mathrm{Pb}(\mathrm{II})$. The removal mechanism can be described as a surface complexation model in which the oxygen-containing surface functional groups (i.e. $\mathrm{C}-\mathrm{O}$ and $\mathrm{C}=\mathrm{O})$ of Tm@CeNPs are responsible for the removal of $\mathrm{Hg}(\mathrm{II})$ and $\mathrm{Pb}(\mathrm{II})$ ions.

Deconvolution spectra of Ce 3d for Tm@CeNPs before and after $\mathrm{Hg}(\mathrm{II})$ and $\mathrm{Pb}(\mathrm{II})$ adsorption show four peaks, which are assigned for $3 \mathrm{~d}_{3 / 2}$ and $3 \mathrm{~d}_{5 / 2}$. The peaks at 885.01 and $891.4 \mathrm{eV}$ are assigned to $3 \mathrm{~d}_{3 / 2}$ and 900.91 and $903.52 \mathrm{eV}$ are assigned to $3 \mathrm{~d}_{5 / 2}$ (Figure 12a,b). Results show that the binding energy decreases, which might be due to the interaction of $\mathrm{CeO}_{2}$ with $\mathrm{Hg}$ (II) or $\mathrm{Pb}(\mathrm{II})$.

Moreover, the high-resolution $4 \mathrm{f}$ spectra of $\mathrm{Hg}(\mathrm{II})$ exhibit two signals at 103.76 and $99.74 \mathrm{eV}$ (Figure 12c), which elucidate the characteristic peaks of $\mathrm{Hg}$ (II) $4 \mathrm{f}_{5 / 2}$ and $4 \mathrm{f}_{7 / 2}$, respectively. The above results show that the mercury is present in its oxidized state $(+2)$ instead of its zero-valence state $[\mathrm{Hg}(0)]$.

Two peaks were appeared at 141.08 and $136.31 \mathrm{eV}$ for $\mathrm{Pb}$ (II) $4 \mathrm{f}_{5 / 2}$ and $4 \mathrm{f}_{7 / 2}$, respectively with an energy separation of $4.9 \mathrm{eV}$, which can be attributed to $\mathrm{PbO}$. Results suggest that $\mathrm{Pb}$ (II) is bonded with the oxygen group on the surface of Tm@CeNPs (Figure 12d). Table 7 shows the binding energy,

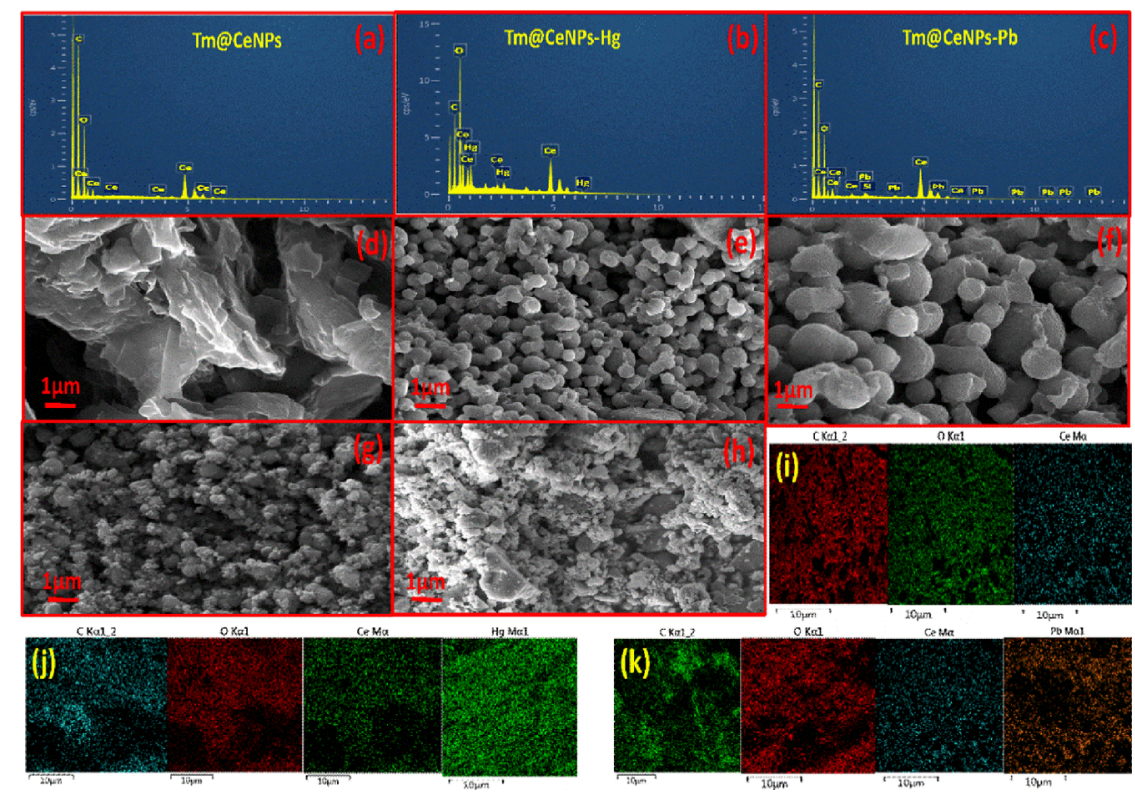

Figure 10. $(\mathrm{a}-\mathrm{c})$ EDX spectra of Tm@CeNPs, Tm@CeNPs-Hg(II), and Tm@CeNPs-Pb(II), respectively, (d-h) FESEM images of dried Tamarind leaves, CeNPs, Tm@CeNPs, Tm@CeNPs-Hg(II), and Tm@CeNPs-Pb(II), and (i-k) mapping images of Tm@CeNPs, Tm@ CeNPs- $\mathrm{Hg}(\mathrm{II})$, and Tm@CeNPs-Pb(II), respectively. 

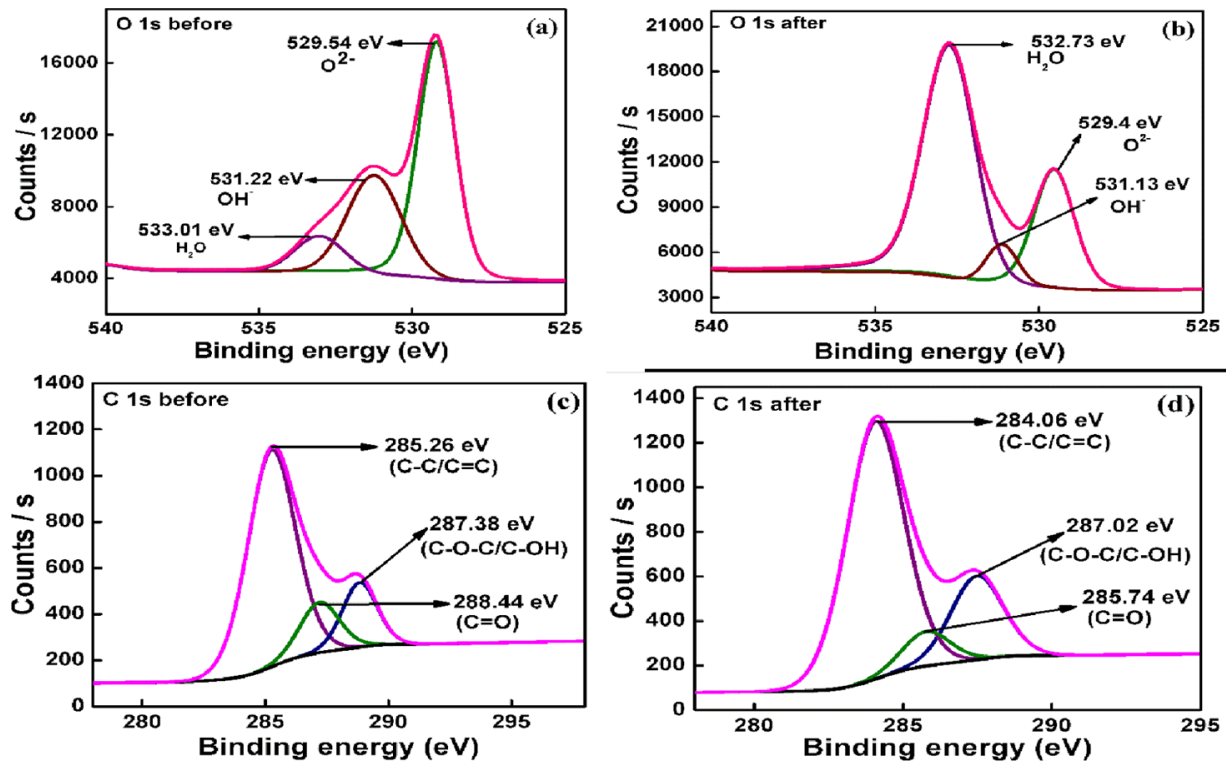

Figure 11. XPS spectra of (a,b) oxygen before and after adsorption and (c,d) carbon before and after adsorption of $\mathrm{Hg}(\mathrm{II})$ and $\mathrm{Pb}(\mathrm{II})$ on $\mathrm{Tm} @$ CeNPs.

Table 7. Binding Energy of Each Element before and after Adsorption on Tm@CeNPs

\begin{tabular}{|c|c|c|c|c|}
\hline & peak & $\mathrm{BE}(\mathrm{eV})$ & $\begin{array}{l}\text { fwhm } \\
(\mathrm{eV})\end{array}$ & $\begin{array}{l}\text { percentage } \\
(\%)\end{array}$ \\
\hline \multirow{8}{*}{$\begin{array}{l}\text { before } \\
\text { adsorption }\end{array}$} & $\mathrm{O}^{2-}$ & 529.54 & 2.0 & 56.57 \\
\hline & $\mathrm{M}-\mathrm{OH}$ & 531.22 & 1.27 & 22.86 \\
\hline & $\mathrm{H}_{2} \mathrm{O}$ & 533.01 & 2.17 & 20.57 \\
\hline & $\mathrm{C}-\mathrm{C} / \mathrm{C}=\mathrm{C}$ & 285.26 & 3.2 & 83.01 \\
\hline & $\mathrm{C}=\mathrm{O}$ & 288.44 & 2.4 & 8.27 \\
\hline & $\mathrm{C}-\mathrm{O}-\mathrm{C} / \mathrm{C}-\mathrm{OH}$ & 287.38 & 1.5 & 8.73 \\
\hline & $\begin{array}{c}\mathrm{Ce}\left(3 \mathrm{~d}_{3 / 2}\right) \& \\
\left(3 \mathrm{~d}_{5 / 2}\right)\end{array}$ & $\begin{array}{r}885.01 \\
891.4\end{array}$ & $2.96,2.96$ & $\begin{array}{l}28.03 \\
15.70\end{array}$ \\
\hline & & $\begin{array}{c}900.91 \\
903.52\end{array}$ & $4.92,2.96$ & $46.52,9.78$ \\
\hline \multirow{12}{*}{$\begin{array}{l}\text { after } \\
\text { adsorption }\end{array}$} & $\mathrm{O}^{2-}$ & 529.4 & 1.83 & 50.55 \\
\hline & $\mathrm{M}-\mathrm{OH}$ & 531.13 & 0.97 & 39.31 \\
\hline & $\mathrm{H}_{2} \mathrm{O}$ & 532.73 & 1.07 & 10.13 \\
\hline & $\mathrm{C}-\mathrm{C} / \mathrm{C}=\mathrm{C}$ & 284.06 & 1.08 & 48.73 \\
\hline & $\mathrm{C}=\mathrm{O}$ & 285.74 & 1.85 & 9.79 \\
\hline & $\mathrm{C}-\mathrm{O}-\mathrm{C} / \mathrm{C}-\mathrm{OH}$ & 287.02 & 2.21 & 41.48 \\
\hline & $\begin{array}{l}\mathrm{Ce}\left(3 \mathrm{~d}_{3 / 2}\right) \& \\
\left(3 \mathrm{~d}_{5 / 2}\right)\end{array}$ & $\begin{array}{l}882.4 \\
889.1\end{array}$ & $5,3.2$ & $\begin{array}{l}24.27 \\
18.50\end{array}$ \\
\hline & & $\begin{array}{l}898.2 \\
900.7\end{array}$ & $3,2.4$ & $24.22,9.38$ \\
\hline & $\underset{\left(4 \mathrm{f}_{7 / 2}\right)}{\operatorname{Hg}(\mathrm{II})\left(4 \mathrm{f}_{5 / 2}\right) \&}$ & 103.76 & 1.09842 & 42.02 \\
\hline & & 99.74 & 1.20359 & 57.98 \\
\hline & $\begin{array}{l}\mathrm{Pb}(\mathrm{II})\left(4 \mathrm{f}_{5 / 2}\right) \& \\
\quad\left(4 \mathrm{f}_{7 / 2}\right)\end{array}$ & 141.08 & 2.70626 & 49.27 \\
\hline & & 136.31 & 2.3946 & 39.39 \\
\hline
\end{tabular}

$\%$ content, and full width at half maximum (fwhm) values of each element before and after adsorption of heavy metal ions.

8.3. X-ray Diffraction. Figure $13 \mathrm{a}$ shows the $\mathrm{X}$-ray diffraction (XRD) patterns of Tm powder, CeNPs, and Tm@CeNPs. The XRD peaks of tamarind powder appear at $25^{\circ} 61^{\prime}, 29^{\circ} 99^{\prime}, 31^{\circ} 87^{\prime}, 35^{\circ} 06^{\prime}, 36^{\circ} 11^{\prime}, 49^{\circ} 35^{\prime}, 59^{\circ} 95^{\prime}$, and $62^{\circ} 69^{\prime}$. The XRD pattern of CeNPs matches with the JCPDS card no. 00-031-0325. The Bragg planes in the CeNPs XRD pattern (020), (110), (112), (200), and (220) confirm the synthesis of nanoparticles. After the formation of the adsorbent, the peaks of CeNPs remain intact in the Tm@ CeNPs. The $d$-spacing value of the crystal lattice is 2.124 ; the crystal structure is hexagonal and centrosymmetric. The average crystal size of particles calculated by $d$-spacing value is $15.24 \mathrm{~nm}$. Lattice strain is 0.0063 , and fwhm of the crystal lattice is 0.5642 .

8.4. Fourier-Transform Infrared Spectroscopy. The FTIR spectra of CeNPs show the characteristic peaks of nanoparticles. The characteristic bands of CeNPs were found in two regions, that is, $1100-1700 \mathrm{~cm}^{-1}$ and $3000-3800 \mathrm{~cm}^{-1}$. In addition to these, there is a band at $770 \mathrm{~cm}^{-1}$ assigned to the $\mathrm{Ce}-\mathrm{O}$ bond. The characteristic band at $3364 \mathrm{~cm}^{-1}$ is assigned to $-\mathrm{OH}$ stretching vibrations of physical adsorbed water or surface hydroxyl groups. The peaks seen at 1390, 1686 , and $1046 \mathrm{~cm}^{-1}$ represent bicarbonate type species and monodentate carbonate species with $\mathrm{O}-\mathrm{C}-\mathrm{O}$ stretching.

In the FTIR spectra of tamarind dried leaves, the characteristic peaks are found at 664, 1038, 1224, 1384, $1692,1745,2912$, and $3308 \mathrm{~cm}^{-1}$. The peak around $1384 \mathrm{~cm}^{-1}$ corresponds to the presence of $\mathrm{N}-\mathrm{H}$ stretching of the amide group. The peak at $1692 \mathrm{~cm}^{-1}$ resembles the carbonyl of carboxylic group peak, and the $1745 \mathrm{~cm}^{-1}$ peak resembles carbonyl $(\mathrm{C}=\mathrm{O})$ stretching of the ester group. Owing to the existence of aromatic ortho disubstituted heterocyclic molecules, an assignment occurs at $664 \mathrm{~cm}^{-1}$ for ATFL indicating a possibility of ring cleavage after the coating of $\mathrm{CeO}_{2}$. The peak around $2912 \mathrm{~cm}^{-1}$ is the characteristic peak of $\mathrm{C}-\mathrm{H}$ stretching and $3308 \mathrm{~cm}^{-1}$ for surface hydroxyl group (Figure 13b).

In FTIR spectra of Tm@CeNPs, all characteristic peaks of CeNPs and Tm powder remain intact with a minor change in the frequency, which might be due to the interaction between the CeNPs and Tm powder. The peak at $3308 \mathrm{~cm}^{-1}$ of $\mathrm{O}-\mathrm{H}$ stretching of $-\mathrm{OH}$ group becomes broad because of $\mathrm{H}$ bonding (3300-3750 $\mathrm{cm}^{-1}$ ) after the formation of Tm@ CeNPs. In the FTIR spectra of Tm@CeNPs after adsorption of $\mathrm{Hg}$ (II) and $\mathrm{Pb}$ (II) metal ions, the decrease in the intensity and wavenumber of peaks indicates the formation of metal- 

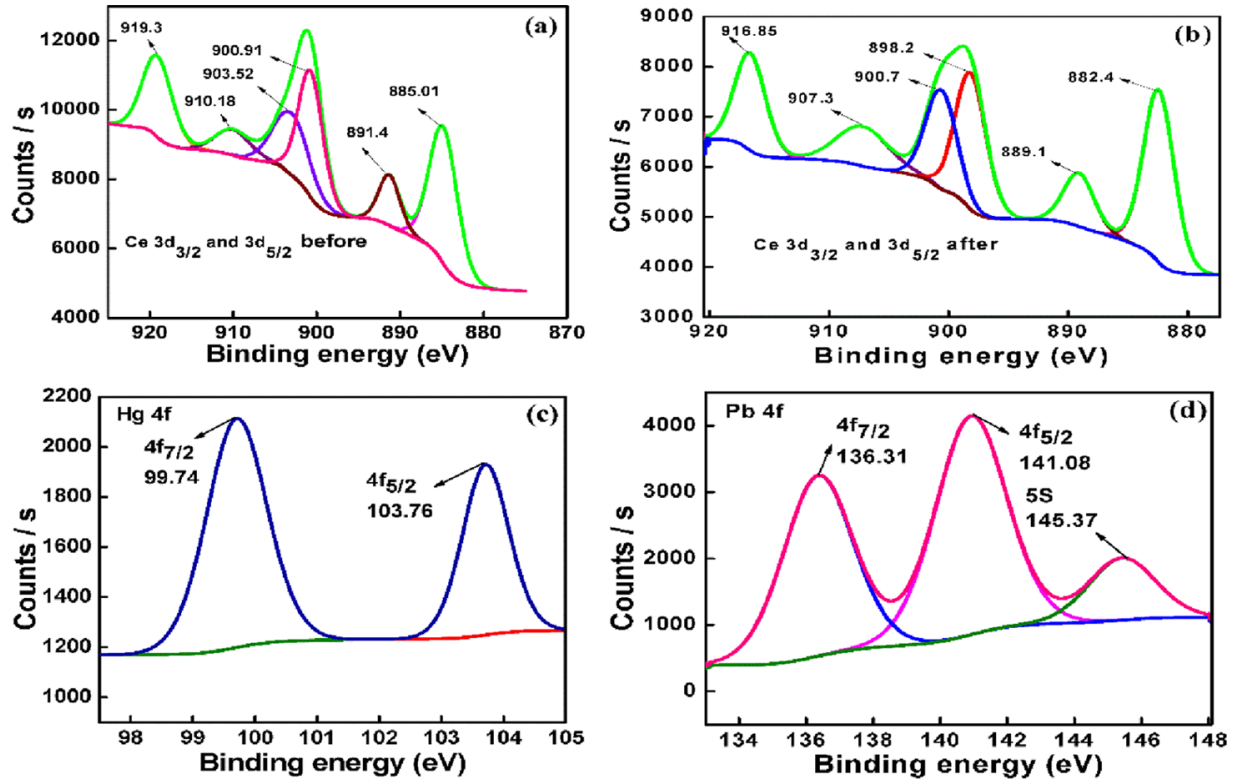

Figure 12. XPS spectra (a,b) of cerium before and after adsorption of $\mathrm{Hg}(\mathrm{II})$ and $\mathrm{Pb}$ (II) on $\mathrm{Tm} @ \mathrm{CeNPs}$ ( $\mathrm{c}, \mathrm{d}) \mathrm{XPS}$ spectra of $\mathrm{Hg}(\mathrm{II})$ and $\mathrm{Pb}(\mathrm{II})$ on adsorption of Tm@CeNPs.
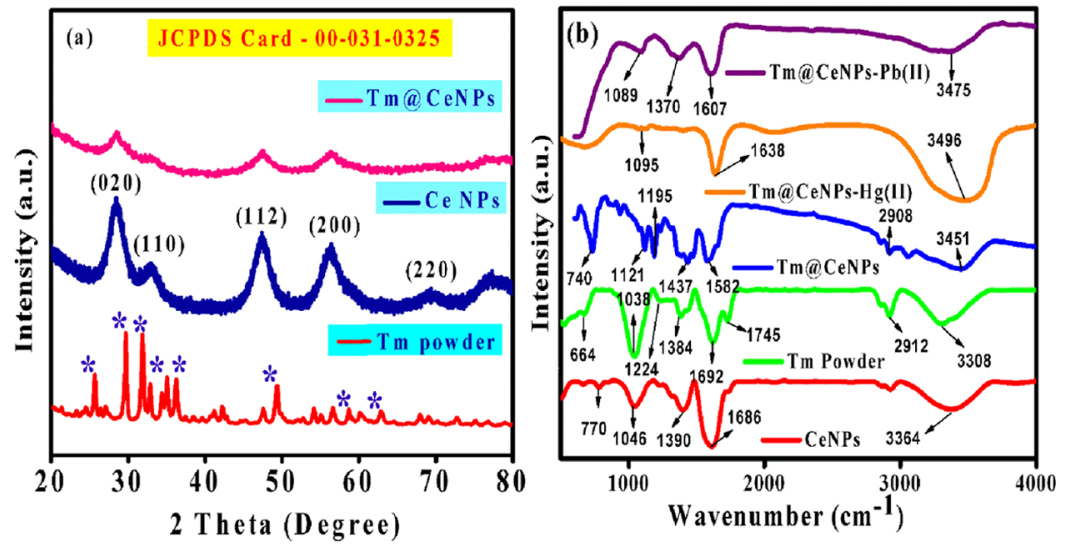

Figure 13. (a) XRD pattern of Tamarind powder, CeNPs, and Tm@CeNPs and (b) Fourier-transform infrared spectroscopy (FTIR) spectra of CeNPs, Tamarind powder, Tm@CeNPs, Tm@CeNPs-Hg(II), and Tm@CeNPs-Pb(II).
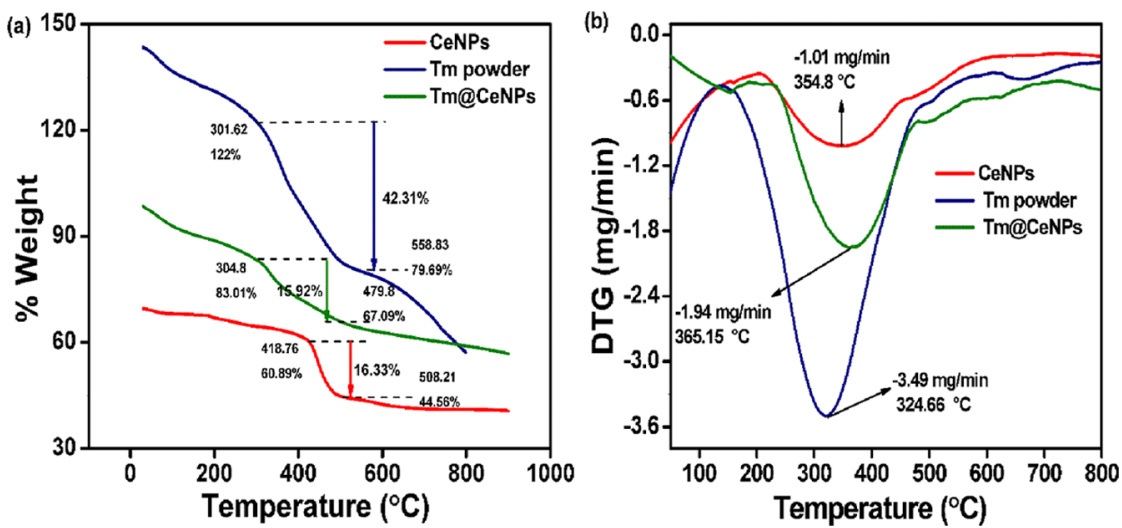

Figure 14. (a,b) TGA and DTA thermograms of CeNPs, Tm powder, and Tm@CeNPs, respectively.

oxygen bonds with their corresponding functional groups (Figure 13b). From the FTIR analysis, the stretching peak of a hydroxyl group $\left(3451 \mathrm{~cm}^{-1}\right)$ gets broadened because of $\mathrm{H}$ bonding (3400-3800 $\mathrm{cm}^{-1}$ ) (Figure 13b).
8.5. Thermogravimetric Analysis-Differential Thermal Analysis. The compositional analysis of the Tm@CeNPs was carried out using thermogravimetric analysis (TGA). The TGA data of CeNPs, Tm powder, and Tm@CeNPs showed no significant weight loss above $150{ }^{\circ} \mathrm{C}$. However, the TGA 


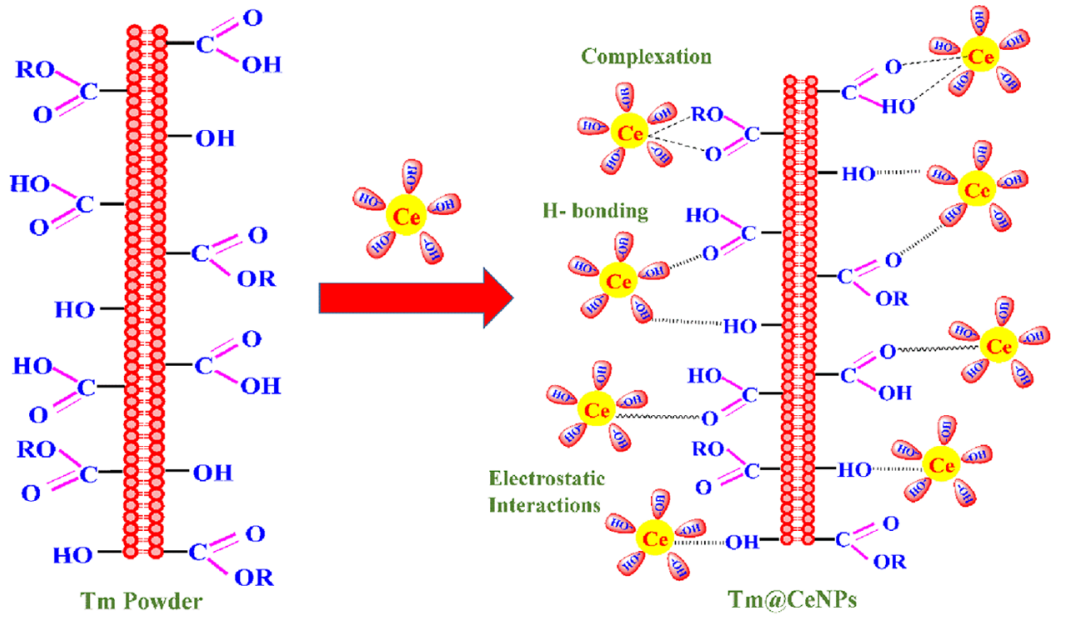

Figure 15. Binding mechanism of CeNPs with tamarind powder.

data for the Tm@CeNPs, CeNPs, and tamarind powder (Figure 14a) showed two independent weight loss steps, the first step at $0-200{ }^{\circ} \mathrm{C}$ and the second step above $200{ }^{\circ} \mathrm{C}$. The second weight loss is highest in tamarind powder, that is, 42.31\%, and lowest in Tm@CeNPs, that is, $15.92 \%$, which indicates that after coating of CeNPs with Tm powder, the thermodynamic stability of the synthesized adsorbent increases. The same result is shown by differential thermal analysis (DTA) studies (Figure 14b).

\section{CONCLUSIONS}

This research studies the adsorption of $\mathrm{Hg}$ (II) and $\mathrm{Pb}$ (II) by tamarind leaf composite. The synthesized adsorbent was successfully utilized for $\mathrm{Hg}$ (II) and $\mathrm{Pb}$ (II) adsorption with maximum adsorption capacity of 200 and $142.85 \mathrm{mg} / \mathrm{g}$, respectively. The surface area of Tm@CeNPs was found to be very high, that is, $412 \mathrm{~m}^{2} / \mathrm{g}$. The adsorption process follows a multilayer type of adsorption and PSO kinetics for both the metal ion adsorption processes. The column study reveals that the multilayer type of adsorption and Yoon-Nelson model fitted best. The mean free energy required for $\mathrm{Hg}$ (II) adsorption is lower than $\mathrm{Pb}(\mathrm{II})$, which means that the $\mathrm{Hg}$ (II) is easily adsorbed on the Tm@CeNPs. The use of tamarind leaves opens a new class of adsorbent for the heavy metal ion removal, as the surface area of dried tamarind leaves is very high. Thermodynamic studies reveal that the adsorption process of heavy metal ion was feasible, spontaneous, and exothermic. Increase in temperature does not favor the adsorption process.

\section{MATERIALS}

All the analytical grade chemicals were commercially available and used without further purification.

10.1. Synthesis. 10.1.1. Synthesis of Ceria Nanoadsorbent. In order to synthesize CeNPs, $0.05 \mathrm{M}$ Ce salt solution was prepared in $100 \mathrm{~mL}$ of absolute ethanol. Then, $\mathrm{NaOH} /$ ethanol solution was added dropwise under vigorous stirring until the color of the solution changed from orange to yellow and finally to a dark brown colloidal sol. The colloidal sol was centrifuged, and the precipitate was collected and repeatedly washed with absolute ethanol and deionized water to remove the impurities.
10.1.2. Pretreatment of TFL. The fresh tamarind leaves were initially washed with $0.01 \mathrm{~N} \mathrm{HCl}$, followed by $0.01 \mathrm{~N}$ $\mathrm{NaOH}$. Then, the TFL was washed thoroughly using distilled water and dried by exposing it to sunlight. The dried TFL was sieved to obtain particles $600 \mu \mathrm{m}$ in size.

10.1.3. Preparation of ATFL. About $30 \mathrm{~g}$ of TFL of $600 \mu \mathrm{m}$ was soaked in $600 \mathrm{~mL}$ of $1 \% \mathrm{CaCl}_{2}$ solution, for $24 \mathrm{~h}$. Then, the soaked TFL was washed with distilled water and dried at $110 \pm 0.5{ }^{\circ} \mathrm{C}$ in an air oven for $2 \mathrm{~h}$.

10.1.4. Preparation of $\mathrm{CeO}_{2}$-Entrapped TFL. About $20 \mathrm{~g}$ of $\mathrm{CeO}_{2} \mathrm{NPs}$ was dissolved in $50 \mathrm{~mL}$ of distilled water in a beaker and placed on a magnetic stirrer at $90{ }^{\circ} \mathrm{C}$ for $30 \mathrm{~min}$. To this, $24 \mathrm{~g}$ of ATFL was added and the suspension was mixed gently and heated in a water bath for $10 \mathrm{~min}$. Then, this solution was transferred to a Teflon lined stainless steel autoclave $(200 \mathrm{~mL})$ and put in the oven at $250{ }^{\circ} \mathrm{C}$ for $2 \mathrm{~h}$. The solid was cooled after the completion of the reaction and washed with $0.05 \mathrm{M}$ perchloric acid and distilled water until the run-off was clear. The precipitate was dried and calcined in the muffle furnace up to $513 \mathrm{~K}$ for $2 \mathrm{~h}$. Figure 15 shows the binding mechanism of CeNPs with tamarind powder. The binding of CeNPs with tamarind via $\mathrm{H}$-bonding, electrostatic interactions, and complexation between - $\mathrm{OH}$ group of CeNPs and functional groups of tamarind, that is, carbonyl of $-\mathrm{COOH},-\mathrm{COOR}$, and $-\mathrm{OH}$

10.2. Batch Experiment. In order to understand the adsorption process of $\mathrm{Tm} @ \mathrm{CeNPs}$ for $\mathrm{Hg}$ (II) and $\mathrm{Pb}(\mathrm{II})$ heavy metal ions, different parameters were studied in fixed range, that is, adsorbent dose $(0.1-0.5 \mathrm{~g}), \mathrm{pH}(3-10)$, initial concentration of heavy metal ions $(10-100 \mathrm{ppb})$, contact time (5-70 $\mathrm{min})$, adsorption/desorption studies, and interfering metal ion (Ca(II), $\mathrm{Al}(\mathrm{III}), \mathrm{Mg}(\mathrm{II}), \mathrm{Fe}(\mathrm{II}), \mathrm{Co}(\mathrm{II}), \mathrm{Ni}(\mathrm{II}))$ at room temperature. After analysis of these parameters, the remaining metal ion concentration was analyzed by using atomic absorption spectroscopy, and the \% adsorption (\% A) and adsorption capacity $\left(q_{\mathrm{e}}\right.$ or $\left.q_{t}\right)$ are calculated by using following eqs $1-3$.

$$
\begin{aligned}
& \% \text { adsorption }(\% A)=\left(C_{\mathrm{i}}-C_{\mathrm{e}}\right) \times 100 / C_{\mathrm{o}} \\
& \text { Adsorption capacity } q_{\mathrm{e}}=V \times\left(C_{\mathrm{i}}-C_{\mathrm{e}}\right) / m \\
& q_{t}=V \times\left(C_{\mathrm{i}}-C_{\mathrm{t}}\right) / m
\end{aligned}
$$


Table 8. Linear and Nonlinear Equations of the Column Model

\begin{tabular}{llr}
\multicolumn{1}{c}{ model } & $\frac{C_{\mathrm{e}}}{C_{\mathrm{i}}}=\frac{\text { non-linear form }}{1+\exp \left(\frac{K_{\mathrm{Th}}}{Q}\left(Q_{\mathrm{Th}} X-C_{\mathrm{i}} V_{\mathrm{eff}}\right)\right)}$ & $\ln \left[\left(\frac{C_{\mathrm{i}}}{C_{\mathrm{e}}}\right)-1\right]=\left(\frac{K_{\mathrm{Th}} Q_{\mathrm{Th}} M}{Q}\right)-K_{\mathrm{Th}} C_{\mathrm{i}} t$ \\
Thomas model & $\frac{C_{\mathrm{e}}}{C_{\mathrm{i}}}=\frac{1}{\exp \left(K_{\mathrm{YN}}(\tau-t)\right)}$ & $\ln \left(\frac{C_{\mathrm{e}}}{C_{\mathrm{i}}-C_{\mathrm{e}}}\right)=K_{\mathrm{YN}} t-\tau K_{\mathrm{YN}}$ \\
Yoon-Nelson & $\frac{C_{\mathrm{e}}}{C_{\mathrm{i}}}=1-\frac{1}{1+\left(\frac{Q^{2}}{K_{\mathrm{Y}} Q_{\mathrm{Y}} m}\right)^{K_{\mathrm{Y}} C_{\mathrm{i}} / Q}}$ & $\ln \left(\frac{C_{\mathrm{e}}}{C_{\mathrm{i}}-C_{\mathrm{e}}}\right)=\frac{K_{\mathrm{Y}} C_{\mathrm{i}}}{Q} \ln \left(\frac{Q^{2}}{K_{\mathrm{Y}} Q_{\mathrm{Y}} m}\right)+\frac{K_{\mathrm{Y}} C_{\mathrm{i}}}{Q} \ln t$ \\
Yan et al. & $\frac{C_{\mathrm{e}}}{C_{\mathrm{i}}}=\left(\frac{1}{1+A \mathrm{e}^{-r t}}\right)^{1 / n-1}$ & $\ln \left[\left(\frac{C_{\mathrm{i}}}{C_{\mathrm{e}}}\right)^{n-1}-1\right]=\ln A-r t$
\end{tabular}

where $C_{\mathrm{i}}, C_{\mathrm{e}}, C_{t}, m, V, q_{\mathrm{e}}$, and $q_{t}$ are initial metal concentration $(\mathrm{ppb})$, equilibrium metal concentration (ppb) at time $t$, the mass of adsorbent $(\mathrm{g})$, the volume of solution $(\mathrm{L})$, adsorption capacity at $C_{\mathrm{e}}$, and adsorption capacity at $C_{t}$, respectively.

10.3. Kinetic Studies. Kinetic-based models describe the mechanism of adsorption and also explain the order of reaction. The adsorption kinetics explains the rate of adsorbate uptake and the contact time of adsorbate on the adsorbent interface. The heavy metal ion adsorption process is significantly time-dependent and pretentious by the chemical and physical properties of adsorbent. Thus, to explore the adsorption mechanism, four different kinetic models-PFO, PSO, IPD, and Elovich ${ }^{43-47}$ were used to study the different kinetic parameters. Linear eqs $4-7$ of the following models are

$$
\begin{aligned}
& \text { PFO } \ln \left(q_{\mathrm{e}}-q_{t}\right)=\ln q_{\mathrm{e}}-k_{1} \times t \\
& \text { PSO } t / q_{t}=1 /\left(k^{2} \times q_{\mathrm{e}}{ }^{2}\right)+t / q_{\mathrm{e}} \\
& \text { Intraparticle diffusion } q_{t}=k_{i} \times \sqrt{ } t+X_{i} \\
& \text { Elovich } q_{t}=(1 / \beta) \ln (\alpha \times \beta \times t)+(1 / \beta) \ln t
\end{aligned}
$$

10.4. Adsorption Equilibrium Studies. Adsorption models explain the $q_{\mathrm{e}}$, adsorption mechanism pathways, mode of adsorbate to interact with an adsorbent, and effectual design of adsorption mechanism. There are several adsorption models (i.e., Langmuir, Freundlich, Temkin, and D-R isotherm models $)^{48-51}$ from which most widely utilized models were used to study the adsorption process, given below as eqs $8-13$

$$
\begin{aligned}
& \text { Langmuir } 1 / q_{\mathrm{e}}=1 /\left(q_{\mathrm{m}} \times K_{\mathrm{L}} \times C_{\mathrm{e}}\right)+1 / q_{\mathrm{m}} \\
& \text { Freundlich } \ln q_{\mathrm{e}}=\ln K_{\mathrm{F}}+1 / n\left(\ln C_{\mathrm{e}}\right) \\
& \text { Temkin } q_{\mathrm{e}}=B T \times \ln \left(A T \times C_{\mathrm{e}}\right) \\
& \text { D-R } \ln q_{\mathrm{e}}=\ln q_{\mathrm{m}}-K \epsilon^{2} \\
& \text { Epsilon } \epsilon=R \times T \times\left(1+1 / C_{\mathrm{e}}\right) \\
& \text { Mean free energy } E_{\mathrm{m}}=1 / \sqrt{ } 2 K
\end{aligned}
$$

10.5. Thermodynamic Studies. The temperature plays a significant role in order to understand the thermodynamics of the adsorption process, that is, in-depth understanding of energetic changes during the adsorption process. Thermodynamic variables, that is, $\Delta G$ (change in Gibbs free energy), $\Delta H$ (change in enthalpy), and $\Delta S$ (change in entropy), ${ }^{52,53}$ were calculated by using equation 14-16.

Equilibrium metal ion concentration:

$$
\ln C_{\mathrm{e}}=-\ln K_{\mathrm{o}}+\Delta H / R T
$$

The $\Delta S$ is calculated by Gibbs-Helmholtz equation,

$$
\begin{aligned}
& \Delta S=(\Delta H-\Delta G) / T \\
& \Delta G=-n R T
\end{aligned}
$$

\section{COLUMN STUDY}

The column studies were done by utilizing fixed adsorbent dose, that is, $2 \mathrm{~g}$; the length and diameter of the column was 30.0 and $1.0 \mathrm{~cm}$, respectively. The used stock metal ion solution was $1000 \mathrm{ppb}$ for $\mathrm{Hg}$ (II) and $\mathrm{Pb}$ (II), and the flow rate was maintained at $5.0 \mathrm{~mL} / \mathrm{min}$. The outlet solution was analyzed after each $10 \mathrm{~min}$ for the residual metal ion concentration. In order to study the complete column study, four different models were utilized, that is, Thomas, YoonNelson, Yan, and Clark. ${ }^{54-57}$ The nonlinear and linear equations of these models are tabulated in Table 8 .

\section{PHYSIOCHEMICAL CHARACTERIZATION}

The surface properties of the adsorbents were analyzed by using $\mathrm{N}_{2}$ adsorption-desorption isotherms with the use of the $\mathrm{BET}$ method. In order to analyze the sample for BET analysis, about $20 \mathrm{mg}$ of the sample was degassed for $3 \mathrm{~h}$ at $300{ }^{\circ} \mathrm{C}$, and then it was used for analysis. The morphology and elemental composition of the adsorbent before and after adsorption were analyzed by FESEM attached with EDX. Additionally, the surface chemistry and chemical state of the element before and after adsorption were determined by XPS. XRD patterns of the samples were collected using a model XRD instrument. $\mathrm{Cu} \mathrm{K} \alpha$ radiation was used in this study. The functionalization of adsorbents was analyzed by FTIR spectra in the range 4000$400 \mathrm{~cm}^{-1}$. TGA and DTA analyses were carried out to the study of characteristic physical changes in adsorbents.

\section{ASSOCIATED CONTENT}

\section{Supporting Information}

The Supporting Information is available free of charge on the ACS Publications website at DOI: 10.1021/acsomega. 8 b01874.

Chemical constituents of green leaves of plant; testing of Tm@CeNPs with industrial wastewater; EDX spectra of leaves of other plants; co-anions study of adsorption; 
and batch experiment for treatment of industrial wastewater (PDF)

\section{AUTHOR INFORMATION}

\section{Corresponding Author}

*E-mail: dsbchoudhary2002@gmail.com.

\section{ORCID}

Dinesh Kumar: 0000-0001-5488-951X

\section{Author Contributions}

D.K. designed the project and organized the research. R.S. and S.R. carried out the experiments, analyzed the data, and wrote the manuscript. All authors reviewed the manuscript.

\section{Notes}

The authors declare no competing financial interest.

No datasets were generated or analyzed during the current study.

\section{ACKNOWLEDGMENTS}

We gratefully acknowledge support from the Ministry of Human Resource Development Department of Higher Education, Government of India under the scheme of Establishment of Centre of Excellence for Training and Research in Frontier Areas of Science and Technology (FAST), for providing the necessary financial support to carry out this study vide letter no, F. no. 5-5/201 4-TS.Vll.

\section{REFERENCES}

(1) Ravindranath, R.; Roy, P.; Periasamy, A. P.; Chen, Y.-W.; Liang, C.-T.; Chang, H.-T. $\mathrm{Fe}_{2} \mathrm{O}_{3} / \mathrm{Al}_{2} \mathrm{O}_{3}$ Micro Boxes for Efficient Removal of Heavy Metal Ions. New J. Chem. 2017, 41, 7751-7757.

(2) Dash, S.; Chaudhuri, H.; Gupta, R.; Nair, U. G.; Sarkar, A. Fabrication and Application of Low-Cost Thiol Functionalized Coal Fly Ash for Selective Adsorption of Heavy Toxic Metal Ions from Water. Ind. Eng. Chem. Res. 2017, 56, 1461-1470.

(3) Nanicuacua, D. M.; Segatelli, M. G.; Corazza, M. Z.; Teixeira Tarley, C. R. Assessment of organosilane-functionalized nano-carbon black for interference-free on-line $\mathrm{Pb}$ (ii) ion enrichment in water, herbal medicines and environmental samples. Anal. Methods 2016, 8, 2820-2830.

(4) Liu, M.; Zhang, B.; Wang, H.; Zhao, F.; Chen, Y.; Sun, Q. Facile crosslinking synthesis of hyperbranch-substrate nanonetwork magnetite nanocomposite for the fast and highly efficient removal of lead ions and anionic dyes from aqueous solutions. RSC Adv. 2016, 6, 6705767071.

(5) Sdiri, A.; Khairy, M.; Bouaziz, S.; El-Safty, S. A Natural Clayey Adsorbent for Selective Removal of Lead from Aqueous Solutions. Appl. Clay Sci. 2016, 126, 89-97.

(6) Khairy, M.; El-Safty, S. A.; Shenashen, M. A. Environmental Remediation and Monitoring of Cadmium. TrAC, Trends Anal. Chem. 2014, 62, 56-68.

(7) El-Safty, S. A.; Khairy, M.; Shenashen, M. A.; Elshehy, E.; Warkocki, W.; Sakai, M. Optical Mesoscopic Membrane Sensor Layouts for Water-Free and Blood-Free Toxicants. Nano Res. 2015, 8, 3150-3163.

(8) Huang, S.; Ma, C.; Liao, Y.; Min, C.; Du, P.; Jiang, Y. Removal of Mercury(II) from Aqueous Solutions by Adsorption on Poly(1amino-5-chloroanthraquinone) Nanofibrils: Equilibrium, Kinetics, and Mechanism Studies. J. Nanomater. 2016, 2016, 7245829.

(9) Uslu, H.; Datta, D.; Azizian, S. Separation of Chromium (VI) from Its Liquid Solution Using New Montmorillonite Supported with Amine Based Solvent. J. Mol. Liq. 2016, 215, 449-453.

(10) Datta, D.; Uslu, H.; Kumar, S. Adsorptive Separation of Copper $\left(\mathrm{Cu}^{+2}\right)$ from an Aqueous Solution Using Trioctylamine Supported Montmorillonite. J. Chem. Eng. Data 2015, 60, 3193-3200.
(11) Cimino, G.; Passerini, A.; Toscano, G. Removal of Toxic Cations and $\mathrm{Cr}(\mathrm{VI})$ from Aqueous Solution by Hazelnut Shell. Water Res. 2000, 34, 2955-2962.

(12) Johnson, P. D.; Watson, M. A.; Brown, J.; Jefcoat, I. A. Peanut Hull Pellets as a Single Use Sorbent for the Capture of $\mathrm{Cu}$ (II) from Wastewater. J. Waste Manage. 2002, 22, 471-480.

(13) Babarinde, N. A. A. Adsorption of Zinc (II) and Cadmium (II) by Coconut Husk and Goat Hair. J. Pure Appl. Sci. 2002, 5, 81-85.

(14) Acemioglu, B.; Alma, M. H. Equilibrium Studies on Adsorption of $\mathrm{Cu}$ (II) from Aqueous Solution onto Cellulose. J. Colloid Interface Sci. 2001, 243, 81-84.

(15) Vaughan, T.; Seo, C. W.; Marshall, W. E. Removal of Selected Metal Ions from Aqueous Solution Using Modified Corncobs. Bioresour. Technol. 2001, 78, 133-139.

(16) Low, K. S.; Lee, C. K.; Ng, A. Y. Column Study on the Sorption of $\mathrm{Cr}(\mathrm{VI})$ Using Quaternized Rice Hulls. Bioresour. Technol. 1999, 68, 205-208.

(17) Peng, X.; Luan, Z.; Ding, J.; Di, Z.; Li, Y.; Tian, B. Ceria Nanoparticles Supported on Carbon Nanotubes for the Removal of Arsenate from Water. Mater. Lett. 2005, 59, 399-403.

(18) Rostamian, R.; Najafi, M.; Rafati, A. A. Synthesis and characterization of thiol-functionalized silica nano hollow sphere as a novel adsorbent for removal of poisonous heavy metal ions from water: Kinetics, isotherms and error analysis. Chem. Eng. J. 2011, 171, 1004-1011.

(19) Mohan, D.; Singh, K. P. Single- and multi-component adsorption of cadmium and zinc using activated carbon derived from bagasse-an agricultural waste. Water Res. 2002, 36, 23042318.

(20) Albadarin, A. B.; Al-Muhtaseb, A. H.; Al-laqtah, N. A.; Walker, G. M.; Allen, S. J.; Ahmad, M. N. M. Biosorption of toxic chromium from aqueous phase by lignin: mechanism, effect of other metal ions and salts. Chem. Eng. J. 2011, 169, 20-30.

(21) Liu, J.; Ma, Y.; Xu, T.; Shao, G. Preparation of zwitterionic hybrid polymer and its application for the removal of heavy metal ions from water. Hazard. Mater. 2010, 178, 1021-1029.

(22) Wang, X.; Lv, P.; Zou, H.; Li, Y.; Li, X.; Liao, Y. Synthesis of Poly(2-aminothiazole) for Selective Removal of $\mathrm{Hg}$ (II) in Aqueous Solutions. Ind. Eng. Chem. Res. 2016, 55, 4911-4918.

(23) Huang, S.; Ma, C.; Liao, Y.; Min, C.; Du, P.; Zhu, Y.; Jiang, Y. Superb adsorption capacity and mechanism of poly(1-amino-5chloroanthraquinone) nanofibrils for lead and trivalent chromium ions. React. Funct. Polym. 2016, 106, 76-85.

(24) Duke, J. A. Handbook of Legumes of World Economic Importance; Plenum Press: New York, USA, 1981; pp 228-230.

(25) Ishola, M. M.; Agbaji, E. B.; Agbaji, A. S. A chemical study ofTamarindus indica (Tsamiya) fruits grown in Nigeria. J. Sci. Food Agric. 1990, 51, 141-143.

(26) Dehesa, M. A.; Jauregui, O.; Cañigueral, S. Estudio Por HPLCMS/MS de Compuestos Fenólicos Presentes Enlashojas De Tamarindus Indica L. Rev. Fitoterapia 2006, 6, 79-82.

(27) Imam, S.; Iqbal, A.; Hasan, M. M. Tvyo Triterpenes Lupanone and Lupeol, Isolated and Identified from Tamarindus Indica. Linn. Pak. J. Pharm. Sci. 2007, 20, 125-127.

(28) Escalona-Arranz, J. C.; Pérez-Rosés, R.; Licea Jiménez, I.; Rodríguez-Amado, J.; Argota-Coello, H.; Cañizares-Lay, J.; MorrisQuevedo, H. J.; Sierra-González, G. Chemical Constituents of Tamarindus Indica L. Leaves. Rev. Cubana Quim. 2010, 22, 65-71.

(29) Parvez, S. S.; Parvez, M. M.; Nishihara, E.; Gemma, H.; Fujii, Y. Tamarindus Indica L. Leaf is a Source of Allelopathic Substance. Plant Growth Regul. 2003, 40, 107-115.

(30) Gupta, V. K.; Agarwal, S.; Saleh, T. A. Synthesis and Characterization of Alumina-Coated Carbon Nanotubes and Their Application for Lead Removal. J. Hazard. Mater. 2011, 185, 17-23.

(31) Moradi, A.; Moghadam, P. N.; Hasanzadeh, R.; Sillanpää, M. Chelating magnetic nanocomposite for the rapid removal of $\mathrm{Pb}$ (ii) ions from aqueous solutions: characterization, kinetic, isotherm and thermodynamic studies. RSC $A d v$. 2017, 7, 433-448. 
(32) Liao, Y.; Cai, S.; Huang, S.; Wang, X.; Faul, C. F. J. Macromol. Rapid Commun. 21/2014. Macromol. Rapid Commun. 2014, 35, 1813. (33) Rao, M. M.; Reddy, D. H. K. K.; Venkateswarlu, P.; Seshaiah, K. Removal of Mercury from Aqueous Solutions using Activated Carbon Prepared from Agricultural By-Product/Waste. J. Environ. Manage. 2009, 90, 634-643.

(34) Venkatesan, K. A.; Srinivasan, T. G.; Rao, P. V. Removal of Complexed Mercury by Dithiocarbamate Grafted on Mesoporous Silica. J. Radioanal. Nucl. Chem. 2003, 256, 213-218.

(35) Li, J.; Zhang, S.; Chen, C.; Zhao, G.; Yang, X.; Li, J.; Wang, X. Removal of $\mathrm{Cu}(\mathrm{II})$ and Fulvic Acid by Graphene Oxide Nanosheets Decorated with $\mathrm{Fe}_{3} \mathrm{O}_{4}$ Nanoparticles. ACS Appl. Mater. Interfaces 2012, 4, 4991-5000.

(36) Bayen, S. P.; Chowdhury, P. Synthesis of Chromatographic Material by Immobilization of Thioacetamide onto Silica Gel for Easy Detection and Removal of Mercury. J. Environ. Chem. Eng. 2015, 3, $70-78$.

(37) Hassan, S. S. M.; Awwad, N. S.; Aboterika, A. H. A. Removal of mercury(II) from wastewater using camel bone charcoal. J. Hazard. Mater. 2008, 154, 992-997.

(38) Pan, S.; Zhang, Y.; Shen, H.; Hu, M. An Intensive Study on the Magnetic Effect of Mercapto-Functionalized Nano-Magnetic $\mathrm{Fe}_{3} \mathrm{O}_{4}$ Polymers and Their Adsorption Mechanism for the Removal of $\mathrm{Hg}$ (II) from Aqueous Solution. Chem. Eng. J. 2012, 210, 564-574.

(39) Peng, L.; Qin, P.; Lei, M.; Zeng, Q.; Song, H.; Yang, J.; Shao, J.; Liao, B.; Gu, J. Modifying $\mathrm{Fe}_{3} \mathrm{O}_{4}$ Nanoparticles with Humic Acid for Removal of Rhodamine B in Water. J. Hazard. Mater. 2012, 209-210, 193-198.

(40) Atia, A. A.; Donia, A. M.; Al-Amrani, W. A. Adsorption/ Desorption Behavior of Acid Orange 10 on Magnetic Silica Modified with Amine Groups. Chem. Eng. J. 2009, 150, 55-62.

(41) Tan, Y.; Chen, M.; Hao, Y. High Efficient Removal of Pb (II) by Amino-Functionalized $\mathrm{Fe}_{3} \mathrm{O}_{4}$ Magnetic Nano-Particles. Chem. Eng. J. 2012, 191, 104-111.

(42) Yang, G.; Tang, L.; Zeng, G.; Cai, Y.; Tang, J.; Pang, Y.; Zhou, Y.; Liu, Y.; Wang, J.; Zhang, S.; Xiong, W. Simultaneous Removal of Lead and Phenol Contamination from Water by Nitrogen-Functionalized Magnetic Ordered Mesoporous Carbon. Chem. Eng. J. 2015, 259, 854-864.

(43) Raghav, S.; Sapna; Kumar, D. Cubical-Shaped Rods of PectinHydroxyapatite Composite for Adsorption Studies of Fluoride by Statistical Method and Adsorption Experiments. ACS Omega 2018, 3, 9675-9688.

(44) Riahi, K.; Chaabane, S.; Thayer, B. B. A Kinetic Modeling Study of Phosphate Adsorption onto Phoenix Dactylifera L. Date Palm Fibers in Batch Mode. J. Saudi Chem. Soc. 2017, 21, S143-S152.

(45) Sapna; Raghav, S.; Nair, M.; Kumar, D. Trimetallic Oxide Entrapped in Alginate Polymeric Matrix Employed for Adsorption Studies of Fluoride. Surf. Interfaces 2018, 13, 112-132.

(46) Lu, X.; Shao, Y.; Gao, N.; Ding, L. Equilibrium, Thermodynamic, and Kinetic Studies of the Adsorption of 2,4dichlorophenoxyacetic Acid from Aqueous Solution by MIEX Resin. J. Chem. Eng. Data 2015, 60, 1259-1269.

(47) Maneechakr, P.; Karnjanakom, S. Adsorption Behaviour of $\mathrm{Fe}(\mathrm{II})$ and $\mathrm{Cr}(\mathrm{VI})$ on Activated Carbon: Surface Chemistry, Isotherm, Kinetic and Thermodynamic Studies. J. Chem. Thermodyn. 2017, 106, 104-112.

(48) Lalhmunsiama; Tiwari, D.; Lee, S.-M. Physico-Chemical Studies in the Removal of $\mathrm{Sr}$ (II) from Aqueous Solutions Using Activated Sericite. J. Environ. Radioact. 2015, 147, 76-84.

(49) Zhang, Y.; Zhao, J.; Jiang, Z.; Shan, D.; Lu, Y. Biosorption of $\mathrm{Fe}(\mathrm{II})$ and $\mathrm{Mn}$ (II) Ions from Aqueous Solution by Rice Husk Ash. BioMed Res. Int. 2014, 2014, 973095.

(50) Erhayem, M.; Al-Tohami, F.; Mohamed, R.; Ahmida, K. Isotherm, Kinetic and Thermodynamic Studies for the Sorption of Mercury (II) Onto Activated Carbon from Rosmarinus Officinalis Leaves. Am. J. Anal. Chem. 2015, 6, 1-10.
(51) Raghav, S.; Kumar, D. Adsorption Equilibrium, Kinetics, and Thermodynamic Studies of Fluoride Adsorbed by Tetrametallic Oxide Adsorbent. J. Chem. Eng. Data 2018, 63, 1682-1697.

(52) Dhillon, A.; Nair, M.; Bhargava, S. K.; Kumar, D. Excellent fluoride decontamination and antibacterial efficacy of $\mathrm{Fe}-\mathrm{Ca}-\mathrm{Zr}$ hybrid metal oxide nanomaterial. J. Colloid Interface Sci. 2015, 457, 289-297.

(53) Rahman, N.; Haseen, U. Equilibrium Modeling, Kinetic, and Thermodynamic Studies on Adsorption of $\mathrm{Pb}(\mathrm{II})$ by a Hybrid Inorganic-Organic Material: Polyacrylamide Zirconium(IV) Iodate. Ind. Eng. Chem. Res. 2014, 53, 8198-8207.

(54) Thomas, H. C. Heterogeneous Ion Exchange in a Flowing System. J. Am. Chem. Soc. 1944, 66, 1664-1666.

(55) Yan, G.; Viraraghavan, T.; Chen, M. A New Model for Heavy Metal Removal in a Biosorption Column. Adsorpt. Sci. Technol. 2001, $19,25-43$.

(56) Yoon, Y. H.; Nelson, J. H. Application of Gas Adsorption Kinetics I. A Theoretical Model for Respirator Cartridge Service Life. Am. Ind. Hyg. Assoc. J. 1984, 45, 509-516.

(57) Clark, R. M. Evaluating the Cost and Performance of FieldScale Granular Activated Carbon Systems. Environ. Sci. Technol. 1987, $21,573-580$. 